\title{
Retrieval of atmospheric parameters from GOMOS data
}

\author{
E. Kyrölä ${ }^{1}$, J. Tamminen ${ }^{1}$, V. Sofieva ${ }^{1}$, J. L. Bertaux ${ }^{2}$, A. Hauchecorne ${ }^{2}$, F. Dalaudier ${ }^{2}$, D. Fussen ${ }^{3}$, F. Vanhellemont ${ }^{3}$, \\ O. Fanton d'Andon ${ }^{4}$, G. Barrot ${ }^{4}$, M. Guirlet ${ }^{4}$, A. Mangin ${ }^{4}$, L. Blanot ${ }^{4}$, T. Fehr ${ }^{5}$, L. Saavedra de Miguel ${ }^{5}$, and \\ R. Fraisse ${ }^{6}$ \\ ${ }^{1}$ Finnish Meteorological Institute, Earth Observation, Helsinki, Finland \\ ${ }^{2}$ Laboratoire Atmosphères, Milieux, Observations Spatiales, Université Versailles St-Quentin, CNRS-INSU, \\ Verrières-le-Buisson, France \\ ${ }^{3}$ Institut d'Aéronomie Spatiale de Belgique, Brussels, Belgium \\ ${ }^{4}$ ACRI-ST, Sophia Antipolis, France \\ ${ }^{5}$ European Space Research Institute (ESRIN), European Space Agency, Frascati, Italy \\ ${ }^{6}$ EADS-Astrium, Toulouse, France
}

Received: 14 January 2010 - Published in Atmos. Chem. Phys. Discuss.: 19 April 2010

Revised: 6 September 2010 - Accepted: 2 December 2010 - Published: 14 December 2010

\begin{abstract}
The Global Ozone Monitoring by Occultation of Stars (GOMOS) instrument on board the European Space Agency's ENVISAT satellite measures attenuation of stellar light in occultation geometry. Daytime measurements also record scattered solar light from the atmosphere. The wavelength regions are the ultraviolet-visible band $248-690 \mathrm{~nm}$ and two infrared bands at 755-774 $\mathrm{nm}$ and at 926-954 nm. From UV-Visible and IR spectra the vertical profiles of $\mathrm{O}_{3}$, $\mathrm{NO}_{2}, \mathrm{NO}_{3}, \mathrm{H}_{2} \mathrm{O}, \mathrm{O}_{2}$ and aerosols can be retrieved. In addition there are two $1 \mathrm{kHz}$ photometers at blue $473-527 \mathrm{~nm}$ and red 646-698 nm. Photometer data are used to correct spectrometer measurements for scintillations and to retrieve high resolution temperature profiles as well as gravity wave and turbulence parameters. Measurements cover altitude region $5-150 \mathrm{~km}$. Atmospherically valid data are obtained in $15-100 \mathrm{~km}$.
\end{abstract}

In this paper we present an overview of the GOMOS retrieval algorithms for stellar occultation measurements. The low signal-to-noise ratio and the refractive effects due to the point source nature of stars have been important drivers in the development of GOMOS retrieval algorithms. We present first the Level $1 \mathrm{~b}$ algorithms that are used to correct instrument related disturbances in the spectrometer and photometer measurements The Level 2 algorithms deal with the retrieval of vertical profiles of atmospheric gaseous constituents, aerosols and high resolution temperature. We divide the presentation into correction for refractive effects,

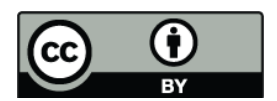

Correspondence to: E. Kyrölä (erkki.kyrola@fmi.fi) high resolution temperature retrieval and spectral/vertical inversion. The paper also includes discussion about the GOMOS algorithm development, expected improvements, access to GOMOS data and alternative retrieval approaches.

\section{Introduction}

GOMOS (Global Ozone Monitoring by Occultation of Stars) is a spectrometer on board the European Space Agency's Envisat satellite (see Bertaux et al., 1991, 2000, 2004, 2010; Kyrölä et al., 2004; ESA, 2001, and http://envisat.esa.int/ handbooks/gomos/). GOMOS uses the method of stellar occultations in monitoring of ozone and other trace gases in the Earth's middle atmosphere (see Fig. 1). The wavelength regions are the ultraviolet-visible band 248-690 $\mathrm{nm}$ and two infrared bands at 755-774 $\mathrm{nm}$ and at 926-954 $\mathrm{nm}$. The species that can be retrieved from these wavelength areas are $\mathrm{O}_{3}$, $\mathrm{NO}_{2}, \mathrm{NO}_{3}, \mathrm{H}_{2} \mathrm{O}, \mathrm{O}_{2}$, neutral density and aerosols. The two photometers work at blue 473-527 nm and red 646-698 nm with a frequency of $1 \mathrm{kHz}$. Photometer data are used to make the scintillation correction for the spectrometer data. From the photometer data it is also possible to retrieve high resolution (resolution of $200 \mathrm{~m}$ ) temperature profiles in the range of $15-40 \mathrm{~km}$ using the spatial separation of rays by chromatic refraction. Moreover, photometer data can be used for middle atmosphere turbulence studies. GOMOS measurements start at the $150 \mathrm{~km}$ tangent altitude and may reach $5 \mathrm{~km}$ if not interrupted by clouds. Atmospherically valid data are obtained in $15-100 \mathrm{~km}$. 


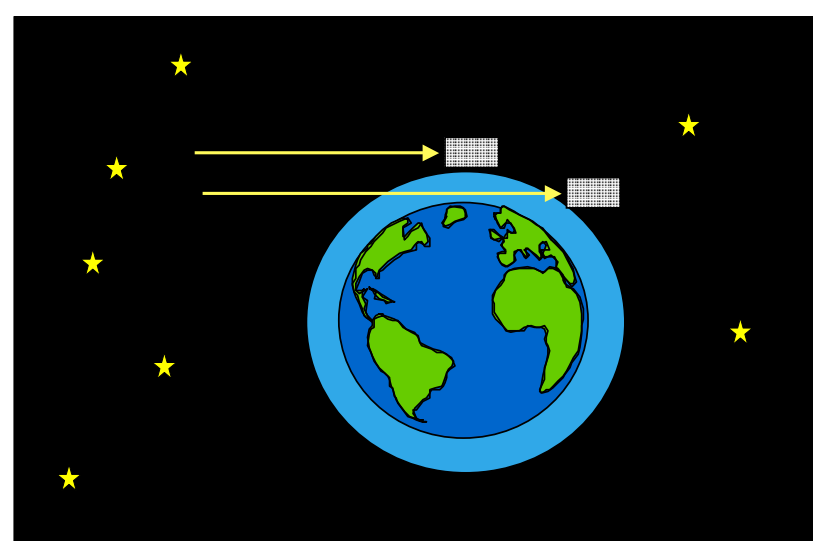

Fig. 1. The principle of the stellar occultation measurement. The measurements above the atmosphere are used to build up the reference spectrum for the star. The measurements through the atmosphere are used to calculate the horizontal transmission spectra. These serve as a starting point for geophysical retrieval.

The main light sources for GOMOS are stars that provide sufficient flux in the spectral range $250-1000 \mathrm{~nm}$ where the GOMOS detectors and the star tracking system work. Stars must be brighter than the visual magnitude 4 and the acceptable temperature range of stars is $3000-30000 \mathrm{~K}$. Examples of stellar spectra measured by GOMOS are shown in Fig. 2 . The figure shows clearly the large differences between the spectra from cool and hot stars.

The point source character of stars and the weakness of their radiation make it necessary to consider several questions that are not relevant to the more familiar solar occultation method (see, e.g. Chu et al., 1989; Glaccum et al., 1996). Light from a far away point source appears as parallel rays or equivalently as plane waves when entering into the atmosphere. In the atmosphere rays are refracted from the original direction and the deflection angle depends on wavelength and the neutral density at the tangent altitude. The originally parallel light rays diverge after the passage through the atmosphere leading to a reduced intensity (see Fig. 3). Moreover, the fluctuations in the neutral density distribution lead to inhomogeneous distribution of intensity, which can be seen as scintillations in the radiation measurements.

The low signal-to-noise ratio means that we must put additional effort on data retrieval from noisy data and we must understand what additional light sources, like auroral and other natural emissions, may compete with the stellar signal. As evident from Fig. 2, different stars provide vastly varying spectra and radiation fluxes. The differences between stars are most important at the edges of the GOMOS spectral range. In the UV-part cool stars radiate very weakly and this is reflected in poor retrieval results for high altitude ozone. In the water vapour band $926-954 \mathrm{~nm}$, on the other hand, cool stars are relatively better than hot stars but the brightness of the star cannot be ignored as Fig. 2 shows.

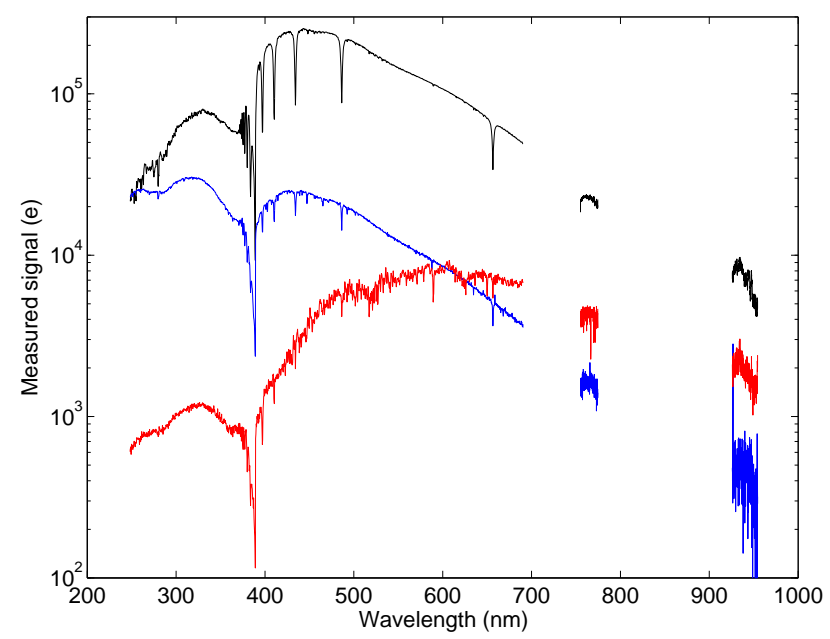

Fig. 2. Star spectra measured by GOMOS. The spectrum of the visually brightest star in the sky, Sirius or $\alpha \mathrm{CMa}$, is shown by the black line. Sirius' visual magnitude is -1.44 and the effective surface temperature (determined from the spectral class) $11000 \mathrm{~K}$. The blue line shows the spectrum for the star $\beta$ Cru with magnitude 1.253 and temperature $30000 \mathrm{~K}$. The red line represents the spectrum of the star $\epsilon$ Car with magnitude 1.86 and temperature $4100 \mathrm{~K}$. The visual magnitudes determine the flux at $550 \mathrm{~nm}$ by $F=F_{\text {ref }} 10^{-m / 2.5}$.

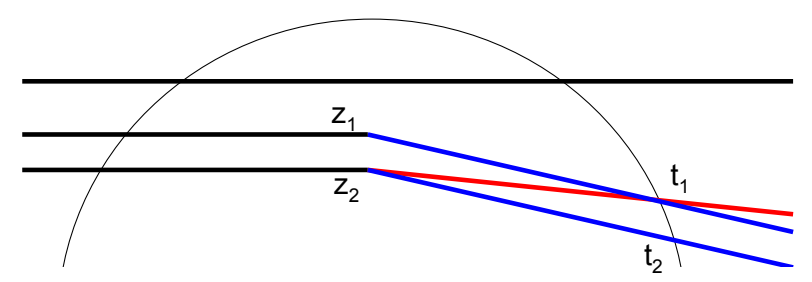

Fig. 3. Chromatic refraction and its impact on detection times of different colours. A measurement at time $t_{1}$ receives the blue light from the tangent point $z_{1}$ and the red light from the tangent point $z_{2}$. If a satellite is assumed to move clockwise along a circular orbit, the density fluctuations near tangent point $\mathrm{z}_{2}$ are first observed at red wavelengths at time $t_{1}$ and later at time $t_{2}$ at blue wavelengths.

Because a half of each orbit is illuminated by the sun, GOMOS detectors are illuminated by scattered solar light, which easily dominates the stellar signal in daytime measurements. This is called background radiation. The twodimensional CCD detectors used by GOMOS make it, however, possible to estimate the background radiation coming from the sun and other extended sources and separate it from the star signal. The former radiation is detected all over the CCD whereas the star radiation is localised. This estimation must be very accurate in order not to distort the weak stellar signal. The separation also leaves noise to the stellar signal. GOMOS occultation retrievals in daytime measurements suffer from inaccurate estimation of the background and their quality is presently low. The solar signal itself 
can be used for atmospheric retrievals in the same way as done with OSIRIS/Odin (Llewellyn et al., 2004) and SCIAMACHY/ENVISAT (Bovensmann et al., 1999) instruments. Algorithms and processing for GOMOS scattered solar light retrievals are under development and they are not discussed in this paper (see Taha et al., 2008, and Tukiainen et al., 2008).

GOMOS is a novel instrument concept - in the past there have been only a few attempts to exploit stellar occultations for studies of the Earth's atmosphere. The first such measurements were made already 40 years ago (Hays and Roble, 1968; Roble and Hays, 1972). A more recent effort is the UVISI instrument onboard the MSX-satellite. It has carried out stellar occultations successfully during 1996-2001, providing samples of ozone profiles in the stratosphere (Yee et al., 2002). Most of the GOMOS data processing algorithms are either completely new or they have been tailored specifically for stellar occultations.

The algorithms discussed here are used in the ENVISAT GOMOS ground segment supported by ESA. The processing is divided into two levels. Level $1 \mathrm{~b}$ deals with the instrument related corrections, geolocation, and the calculation of transmissions that are the basis for the Level 2 processing. Level 2 deals with the retrieval of atmospheric parameters like constituent and temperature profiles. The algorithms have been developed in the contract between ESA and the ACRI-ST company in Sophia-Antipolis, France. The scientific institutes, Finnish Meteorological Institute, Service d'Aéronomie and Institut d'Aéronomie Spatiale de Belgique, form the GOMOS Expert Support Laboratory-coalition (ESL) that has been the scientific partner of ACRI in the algorithm development.

The GOMOS Level $1 \mathrm{~b}$ and Level 2 algorithms have been written down in great detail (presently in 827 pages) in the GOMOS Detailed Processing Model-document (GOMOS ESL, 1998). The more scientific description of the GOMOS processing is the GOMOS Algorithm Theoretical Basis document (ATBD, presently 74 pages) http://envisat.esa.int/ instruments/gomos/atbd/. The aim of this paper is to describe relatively concisely all the methods that are used to process raw GOMOS data to atmospheric profiles of trace gases and temperature. The emphasis is in the scientific justification of the selected processing algorithms. The general GOMOS overview, validation, error analysis and scientific results are discussed in other papers of this special issue.

The GOMOS data processing algorithms described in this paper are used by the ESA operational processor version 5 (It corresponds to the version 6 of the ACRI's GOMOS processing prototype GOPR). This version deviates only slightly from the earlier processor version 4 . The differences to the upcoming version 6 are discussed in Sect. 14.

Section 2 presents what is known about the physics involved in the GOMOS measurements. This part concerns, therefore, our understanding of the GOMOS forward problem. We will concentrate on processes that are essential in the understanding of the GOMOS data retrieval algorithms. Section 3 summarises briefly the properties of the GOMOS instrument. Section 4 discusses the all important geolocation for GOMOS measurements. Section 5 focuses on the Level $1 \mathrm{~b}$ processing where instrumental corrections are applied. In Sect. 6 we present briefly the photometer Level $1 \mathrm{~b}$ processing, which is very similar to the spectrometer processing. Error estimation for transmissions are presented in Sect. 7. Introduction to the Level 2 processing is given in Sect. 8. Refraction corrections that are essential for stellar occultation measurements are given in Sect. 9. The retrieval of high resolution temperature from photometer time delay is presented in Sect. 10. Sections 11-13 deal with retrieval of atmospheric parameters from transmissions. In Sect. 14 we present the main developments of the GOMOS processing in the past and expected future improvements. Section 15 gives basic information about the access to GOMOS data and related documentation. Section 16 discusses alternative methods for GOMOS retrieval.

\section{GOMOS measurement physics}

An occultation measurement can be thought as a measurement of the atmospheric transmission between a source and the instrument (for references and reviews for occultation method, see Elliot, 1979; Hays and Roble, 1968; Smith and Hunten, 1990; Kyrölä et al., 1993; Bertaux et al., 2010). Transmission cannot be measured directly but it needs to be calculated from measurements above and through the atmosphere. As a first guess the transmission can be modelled with the well-known Beer-Lambert law

$T_{\mathrm{ext}}=e^{-\tau}$

where the optical depth $\tau$ is given by

$\tau(\lambda)=\sum_{j} \int_{\ell} \sigma_{j}(\lambda, T(\bar{r}(s))) \rho_{j}(\bar{r}(s)) d s$.

Here $\rho_{j}$ 's are the constituent densities and $\sigma_{j}$ 's are the absorption or scattering cross-sections. Cross sections depend on wavelength and often also on temperature. The integration is made along the light path joining the instrument and the source. The modelled transmission gives the desired connection between measurements and the geophysically interesting constituent profiles.

In occultation measurements the Beer-Lambert law alone is not able to explain observed transmissions. A parallel ray bundle from a star will be strongly disturbed by refractive effects in the atmosphere. The following effects can be identified:

1. chromatic bending of rays,

2. refractive dilution,

3. scintillations. 
A nearly exponential decrease of atmospheric neutral density leads to a bending of light rays propagating tangentially with respect to the atmosphere. The bending angle increases with a decreasing tangent altitude. Refraction transforms parallel incident rays into a diverging beam. This results in dilution of the related intensity, see Fig. 3. The dependence of the refractive index on wavelength leads also to a spatial separation of rays of different colours. As shown in Fig. 3, spatial separation of rays takes place not only inside the atmosphere but the separation increases in the free propagation after the atmosphere. Any instantaneous multi-wavelength measurement of a stellar spectrum through the atmosphere is, therefore, not connected to a unique ray connecting the instrument and the star. If we label rays by their tangent heights, we see that at a given instant of time a measurement will be characterised by a range of tangent heights. If we want to attach only one tangent height we have to combine data from measurements at different observation times.

The neutral air density distribution, the origin of refraction, includes irregularities that are generated by internal atmospheric gravity waves and various processes generating turbulence. The characteristic scales range from a few kilometres down to a dissipation scale, which is typically smaller than $1 \mathrm{~m}$. These air density irregularities lead to a variation in the bending angle and therefore also in the transmitted intensity. Variations are called scintillations. Largest scale irregularities (associated with internal gravity waves) are strongly stretched in horizontal direction. The interaction of stellar light with these structures can be described in the geometric optics approximation. It leads to random focusing and defocusing of light rays. For description of scintillations that are caused by small-scale irregularities generated by isotropic turbulence, the diffraction theory needs to be used. For further explanation, see Sofieva et al. (2009).

During daytime measurements GOMOS CCD's are illuminated by the sunlight scattered in the atmosphere one or more times. There may also appear so-called external stray light that originates from the sun illuminated parts of the satellite or atmosphere not directly in the FOV of GOMOS. As already mentioned, scattered sunlight can be used for atmospheric retrieval (not discussed in this paper) but at the same time this part is unwished background radiance that needs to be removed from the star related occultation signal before the retrieval based on Eq. (1). Background radiation can also be generated by auroral and atmospheric emissions.

Clouds are usually the factor that terminates an occultation. Clouds also affect GOMOS retrievals in some cases. Noctilucent clouds (NLC) reside high in the atmosphere (about $82 \mathrm{~km}$ ). NLCs are optically (also vertically) thin and the star tracking is not interrupted. NLCs are easily detected during daytime from increased scattered sunlight in photometers and spectrometers (see Pérot et al., 2010, in this special issue). The background radiance removal, however, does not work correctly for very thin sources of radiation and this produces erroneous transmission values. During night- time the background removal is not used but the contribution to transmission is too small to be detected in individual occultations.

\section{GOMOS instrument}

GOMOS is a medium resolution spectrometer (see Fig. 4). Spectrometers A1 and A2 cover the UV-visible wavelength region 248-690 nm with 1416 pixels with the spectral width $0.31 \mathrm{~nm}$. The spectral resolution is $0.8 \mathrm{~nm}$. The spectrometer B1 covers $755-774 \mathrm{~nm}$ with $4200.045 \mathrm{~nm}$ wide pixels. The spectral resolution is $0.13 \mathrm{~nm}$. The spectrometers B2 covers $926-954 \mathrm{~nm}$ with $5000.052 \mathrm{~nm}$ wide pixels. The spectral resolution is $0.13 \mathrm{~nm}$. The two photometers work at blue $473-527 \mathrm{~nm}$ and red $646-698 \mathrm{~nm}$ wavelengths at a frequency of $1 \mathrm{kHz}$ (see Popescu and Paulsen, 1999).

The high sensitivity requirement (stars are weak sources of light) down to $250 \mathrm{~nm}$ was a significant design driver and led to an all reflective optical system design for the UVIS part of the spectrum and to a functional pupil separation between the UVIS and the IR spectral regions. Due to the requirement of operating with very faint stars (down to magnitude 4) the sensitivity requirement to the instrument is very high. Consequently, a large telescope $(30 \mathrm{~cm} \times 20 \mathrm{~cm}$ aperture $)$ had to be used to collect sufficient signal. Detectors with high quantum efficiency and very low noise had to be developed to achieve the required signal-to-noise ratios.

GOMOS includes a slit to limit the background radiation (mainly solar radiation scattered from the atmosphere) entering to the detectors. The GOMOS star tracker is sensitive inside the range $600-1000 \mathrm{~nm}$. The star tracker needs to keep the star image in the centre of the slit with the accuracy of one pixel. The pointing stability is better than 40 microradians. The star tracker is able to follow a star down to $5-20 \mathrm{~km}$. The altitude limit depends on the qualities of a star, the state of the atmosphere (e.g., clouds), and the limb illumination condition. GOMOS observes only setting stars. Acquisition of a setting star is much easier than a rising star (due to refraction) and getting both modes was impossible due to demanding visibility requirements in the Envisat platform design.

\section{Geolocation}

The accurate geolocation is of central importance for all satellite instruments. This is especially important for limb viewing instruments where the accuracy of the vertical geolocation affects directly the accuracy of vertical profiles. For GOMOS stars provide excellent means to get accurate vertical knowledge of measurements.

Each GOMOS measurement of the atmospheric transmission is geolocated. Several different factors contribute to this: orbit of the satellite, shape of the Earth, state of the atmosphere, and stellar co-ordinates. In the absence of refraction, 


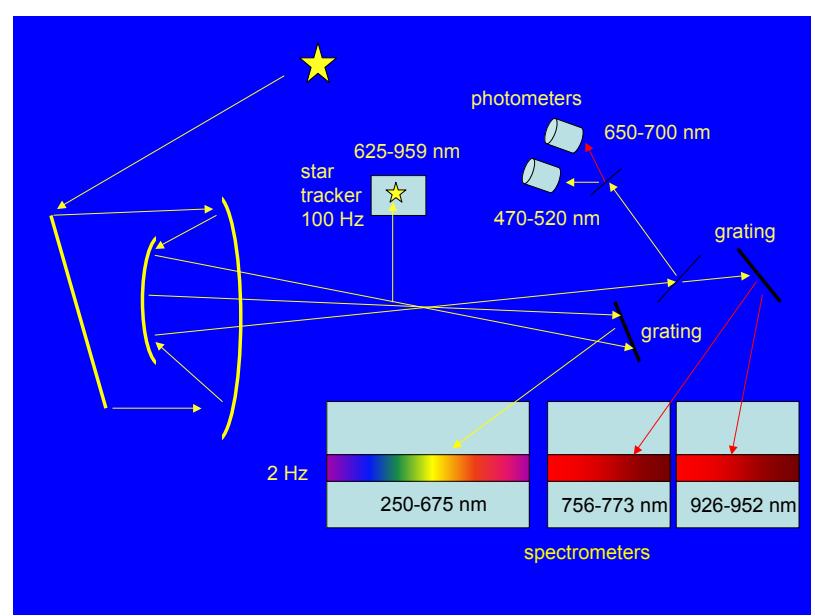

Fig. 4. GOMOS instrument optical layout.

the GOMOS line-of-sight (LOS) is defined by the direction of the star and the location of the Envisat. Geometry and scales of a GOMOS measurement are shown in Fig. 5. The LOS varies from $28^{\circ}$ to $22^{\circ}$ below the satellite's horizontal plane. As a result, for a $28^{\circ} \mathrm{LOS}$, a positioning error $\Delta L$ "along track" (along the orbit) will produce an error $\Delta z$ for the altitude of the LOS tangent height

$\Delta z=\Delta L \cos 28^{\circ} \approx 0.5 \Delta L$

The GOMOS geolocation requires, therefore, a good orbit determination (about $50 \mathrm{~m}$ accuracy) and accurate timing of measurements. The direction to the star must take into account the proper motion of the star, the parallax effect (small), and the aberration of light (Karttunen et al., 2007). The aberration depends on the time of the year (the change in the orbital velocity of the Earth during year) giving the maximum aberration angle of $10^{-4}$ radian. This angle, projected on the limb, would yield an error of about $300 \mathrm{~m}$ in altitude if not accounted for.

The ENVISAT orbit information can be obtained from the orbital data in the GOMOS Level 0 data. Depending on the time delay of the processing with respect to the measurement, there may be also more accurate orbit data available. The shape of the Earth is approximated by the well-known model WGS84.

For the near real time processing, made within $3 \mathrm{~h}$ after the measurements, the atmospheric profile is computed from the ECMWF $24 \mathrm{~h}$ forecast (made the day before) for levels up to $1 \mathrm{hPa}$ (about $45 \mathrm{~km}$ ) and completed by the climatological model MSIS90 model above $1 \mathrm{hPa}$. The final processing is using the ECMWF analysis up to $1 \mathrm{hPa}$. In both cases, a continuous density profile is built up, satisfying the hydrostatic law.

Because of the atmospheric refraction, light from a star to GOMOS does not follow a straight line. A full ray tracing

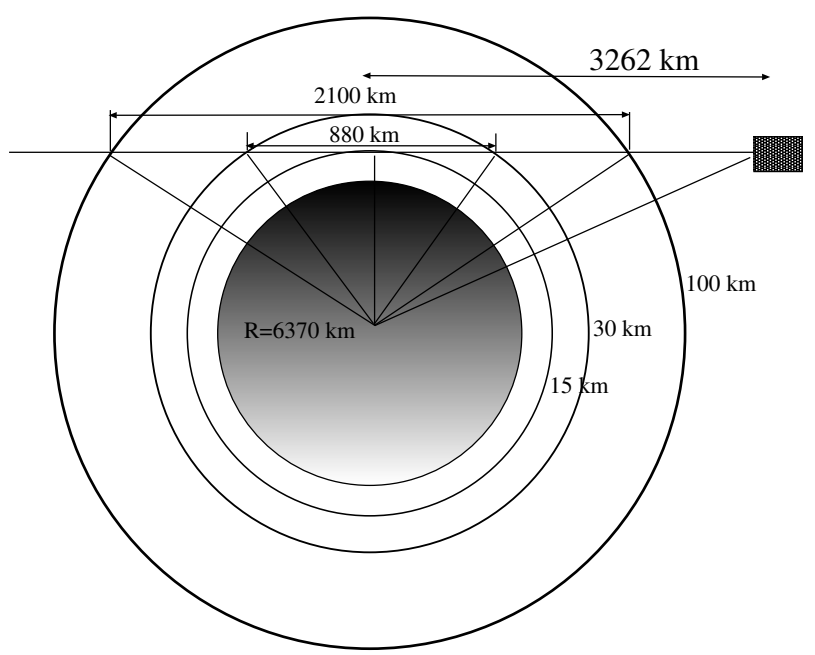

Fig. 5. Length scales of GOMOS measurements. The satellite (Envisat) altitude is assumed to be $800 \mathrm{~km}$.

calculation is performed to compute the path of stellar light. The refracted path is determined from the equation

$\frac{d}{d s}\left(n \frac{d \boldsymbol{r}}{d s}\right)=\nabla n$.

The satellite position and the stellar direction provide the boundary conditions. The source term is produced by the gradient of the refractive index $n$. The refraction is computed at several points along the path, taking into account the atmospheric model and the index of refraction which varies with wavelength according to the Edlen's law

$n=1+\frac{10^{-6}}{1.00062}\left(83.4213+\frac{24060.30}{130-\lambda^{-2}}+\frac{159.97}{38.9-\lambda^{-2}}\right)$

Here the wavelength $\lambda$ is expressed in micrometers. The overall multiplicative factor $1 / 1.00062$ is introduced to account for the deviation from the ideal gas law in the pressure range relevant to the stratosphere. The approximation applied in this calculation is that there is no contribution from density gradients other than the ones in the plane determined by GOMOS, the star and the Earth's centre.

Besides refraction, an important factor for the occultation geometry is the angle of the occultation with the orbital plane. We characterise obliquity of occultation by the angle $\theta$ between the motion of the line of sight with respect to the atmosphere and the direction of the Earth's centre. Figure 6 shows the tangent altitude change in a short occultation (obliquity near zero) and in a long occultation (large obliquity). Figure 7 shows how the vertical sampling distance differs in the occultations of Fig. 6.

Figures 8 and 9 show how the GOMOS measurements probe the atmosphere in short and long occultations. The occultations are the same used in Figs. 6-7. We have shown the movement of the tangent point in latitude-longitude values 


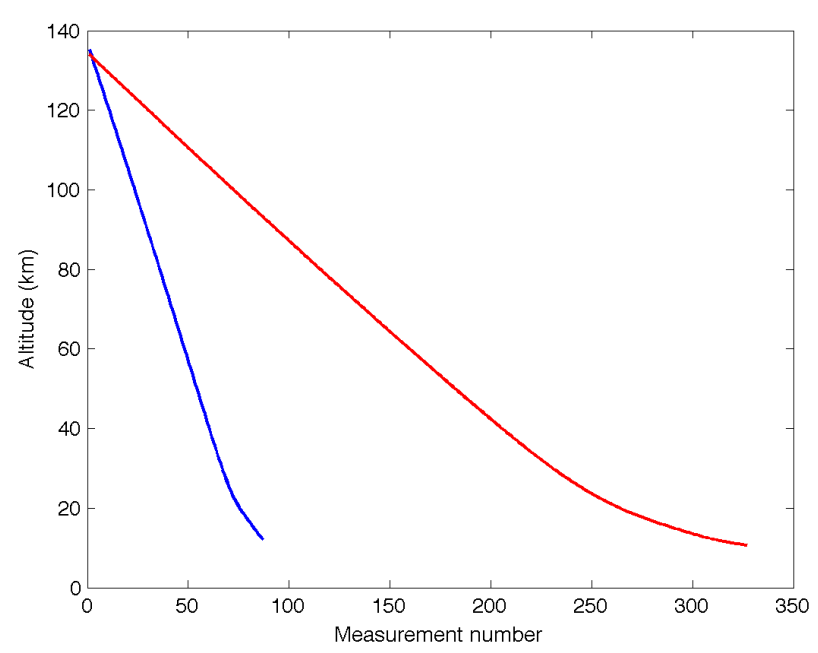

Fig. 6. Tangent point movement during the occultation. The blue line represents a short occultation of $44 \mathrm{~s}$ and the red line a long occultation of $164 \mathrm{~s}$. The refraction effect is to decrease the vertical velocity of the LOS for altitudes below $40 \mathrm{~km}$.

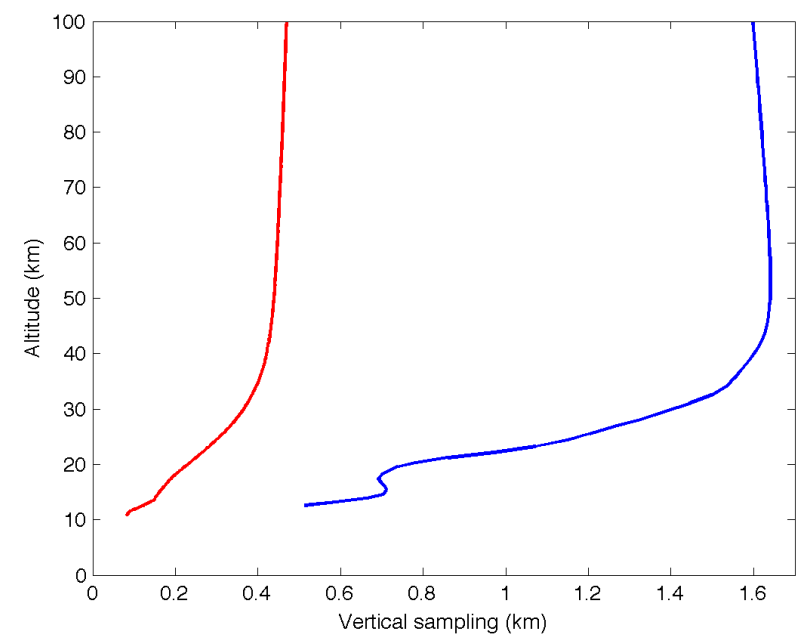

Fig. 7. Tangent point vertical sampling distance as a function of altitude. The blue line represents a short occultation of $44 \mathrm{~s}$ and the red line a long occultation of $164 \mathrm{~s}$. The off-orbital occultation (red) samples the atmosphere with a better vertical resolution. The temporal sampling is in both cases the nominal $0.5 \mathrm{~s}$.

and the latitude-longitude values of ray tracing paths. From the geometry we know that points around the tangent point contribute strongest to the horizontal columns. In the short occultations the tangent point is almost stationary in latitudelongitude coordinates. In the long occultations the movement of the tangent point can be more than $10^{\circ}$ in latitude and longitude.

An important part of the geolocation is to determine the illumination condition of the measurement. Table 1 provides

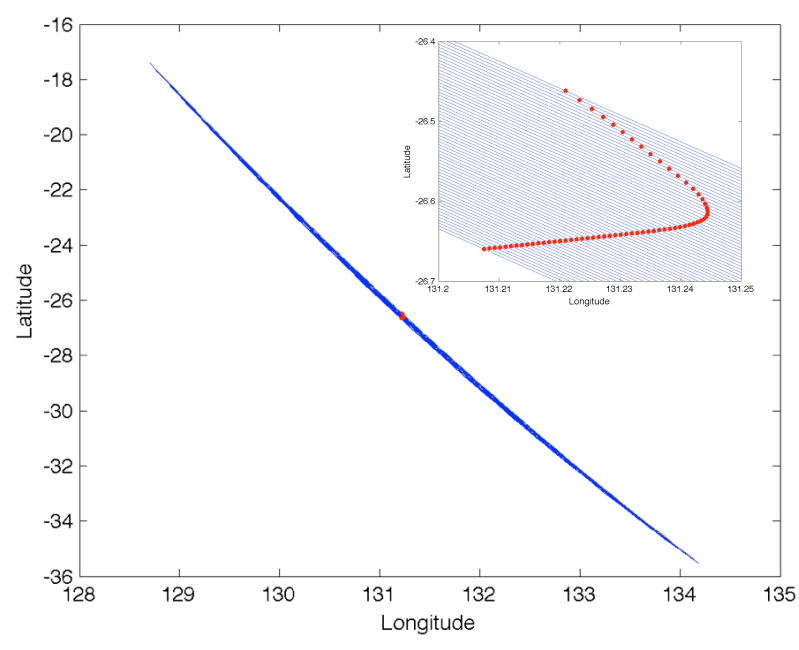

Fig. 8. Geographical coverage of a short GOMOS occultation. The duration of the occultation is $44 \mathrm{~s}$ and the obliquity 3.9. The red line, hardly discernible in the centre of the main figure, gives the latitudelongitude values of the tangent points below $100 \mathrm{~km}$. The inserted figure shows the zoom of the tangent point location. The blue lines show the latitude-longitude projections of the the ray tracing paths below $100 \mathrm{~km}$.

the definition of the illumination flag of GOMOS measurements. Stellar occultations are naturally working best when there is a full dark limb condition (illumination flag $=0$ ). In bright limb conditions scattered solar light easily dominates the stellar signal and retrieval is difficult. The full dark limit of Table 1 constrains strongly the amount of scientifically usable data and therefore more relaxed limits are usually applied without evident corruption of data. Almost all scientific work so far has been using only dark limb measurements and the dark limb is usually defined by requiring the solar zenith angle at the tangent point to be larger than $107^{\circ}$. This is a less restrictive constraint than the full dark case in Table 1, which requires the solar zenith angle at the tangent point to be larger than $110^{\circ}$ and the solar zenith angle at the satellite position to be larger than $120^{\circ}$. The geophysical validation of measurements with different illumination conditions have been presented in Meijer et al. (2004) and van Gijsel et al. (2010).

\section{Level 1b: spectrometer data processing}

\subsection{Wavelength assignment}

The nominal wavelength assignment is carried out using the calibration auxiliary product and the spectral shifts identified using data from the star tracker. The nominal wavelength assignment, corresponding to a perfect star tracking, is provided by the spectral assignment of one CCD column and by the spectral dispersion law of the spectrometers determined 


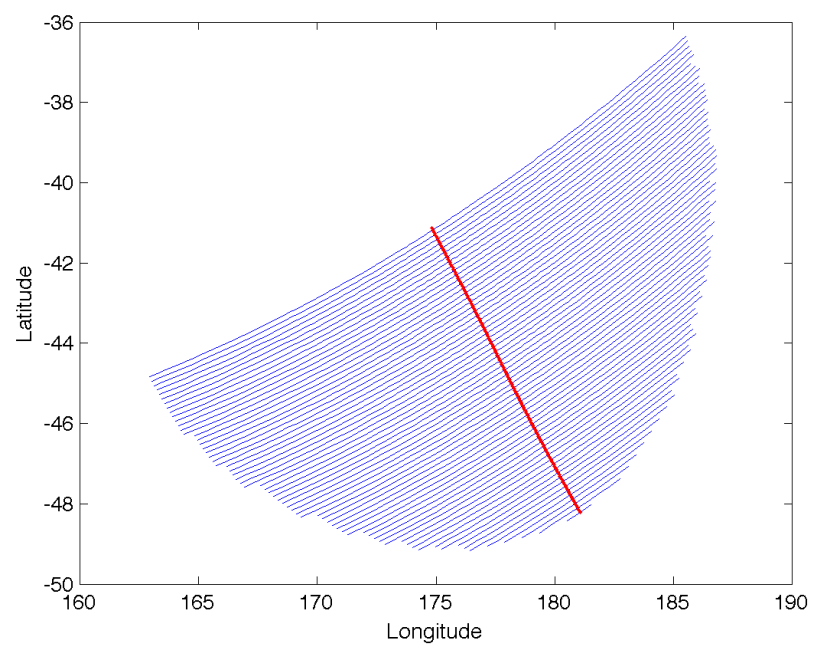

Fig. 9. Geographical coverage of a long GOMOS occultation. The duration of the occultation is $164 \mathrm{~s}$ and the obliquity 83.5 . The red line gives the latitude-longitude values of the tangent points below $100 \mathrm{~km}$. The blue lines show the latitude-longitude values of the the ray tracing paths below $100 \mathrm{~km}$. The occultation starts from the right lower side and moves to the centre of the figure.

in the on-ground characterisation. Spectral shifts due to vibrations and imperfect tracking are estimated by the pointing data history from the SATU (Star Acquisition Tracking Unit). These shifts are used to spectrally assign each CCD column during each spectrometer measurement.

The SATU output provides the shift in horizontal (spectral) and vertical (spatial) directions. Mean SATU output data are computed at a frequency of $2 \mathrm{~Hz}$ and it is used to compute the physical and spectral shifts of the star signal on the spectrometer CCD arrays. The mean spatial shift $(2 \mathrm{~Hz})$ expressed in fraction of the spectrometer B2 CCD lines (or pixels) is plotted in Fig. 10.

\subsection{Bad pixels, cosmic rays and modulation signal}

Bad CCD pixels are specified in the bad pixels list coming from the GOMOS calibration database. The initial list is defined by the on-ground characterisation of GOMOS. This list is regularly updated by the GOMOS in-flight calibration process (Uniformity monitoring mode). There is no on-line detection of bad pixels but the cosmic rays correction processing may prevent use of unexpected bad pixels. Once bad pixels are identified, two complementary actions are performed: (1) the bad pixels are flagged and are ruled out from any further processing. (2) New values in ADU (Analog to Digital Unit) are interpolated from neighbouring pixels by a median filter but they are not used in the further processing.

The CCD detectors are sensitive to high energy particles arriving from the Earth's radiation belts, interplanetary space or interstellar medium. They may also be generated by radioactive decay of impurities in the spacecraft and GOMOS
Table 1. Illumination flag for GOMOS products. SZA is the solar zenith angle.

\begin{tabular}{|c|c|c|}
\hline Flag & Term & Requirement \\
\hline 0 & full dark & $\begin{array}{l}\text { Not in bright limb nor twilight nor } \\
\text { straylight conditions. }\end{array}$ \\
\hline 1 & bright & $\begin{array}{l}\text { SZA at tangent point }<97^{\circ} \text { for at least } \\
\text { one measurement with altitude at tan- } \\
\text { gent point }<50 \mathrm{~km} \text {. }\end{array}$ \\
\hline 2 & twilight & $\begin{array}{l}\text { Not in bright } \operatorname{limb} \text { and SZA at tan- } \\
\text { gent point }<110^{\circ} \text { for at least one mea- } \\
\text { surement with altitude at tangent point } \\
<100 \mathrm{~km} \text {. }\end{array}$ \\
\hline 3 & straylight & $\begin{array}{l}\text { Not in bright limb and SZA of } \\
\text { ENVISAT }<120^{\circ} \text { for at least one } \\
\text { measurement. }\end{array}$ \\
\hline 4 & $\begin{array}{l}\text { twilight }+ \\
\text { straylight }\end{array}$ & $\begin{array}{l}\text { Not in bright limb and both conditions } \\
\text { for twilight and for straylight are veri- } \\
\text { fied. }\end{array}$ \\
\hline
\end{tabular}

materials. A cosmic ray will produce an additional charge in a single pixel or in several pixels if the angle of incidence with respect to the surface of the CCD is small. This phenomenon is seen in all space-flying CCDs.

When the full CCD image is available, the standard way to identify the cosmic hits is to pass a median filter on the image and to compare the content of each pixel to the median value of the window centred on this pixel. For GOMOS, we do not get a full CCD image. Rather, we have several blocks of lines electronically binned together (three per $\mathrm{CCD}$ ) at each exposure of $0.5 \mathrm{~s}$. Therefore, a pseudo-image is reconstituted for each measuring band of CCDs: the top line of the image being the first measurement in the band, the second line being the second measurement, and so on for a whole occultation. We assume here that a pixel has only a very small chance to be hit by a cosmic ray during two consecutive measurements.

This abnormal CCD response is eliminated by a median filtering in both spectral and temporal directions. The content of each pixel is compared to the median value of the filtering window. A cosmic hit is detected if this difference is greater than a given threshold. This threshold value depends of the gain index of the CCD. Threshold values for the four different gain index are read in the Level $1 \mathrm{~b}$ processing configuration product. The value of the corresponding sample is replaced by the computed median value. It is flagged and not used further in the processing. In bright limb condition cosmic ray processing is disabled.

After the launch it was discovered that the electronic chain offset level shows a small variation. This modulation has a reproducible pattern in successive samples and an amplitude of 0.5 to $1.5 \mathrm{ADU}$ (changing with the specific CCD A1 or A2). If the measurement is not towards the bright limb, a 


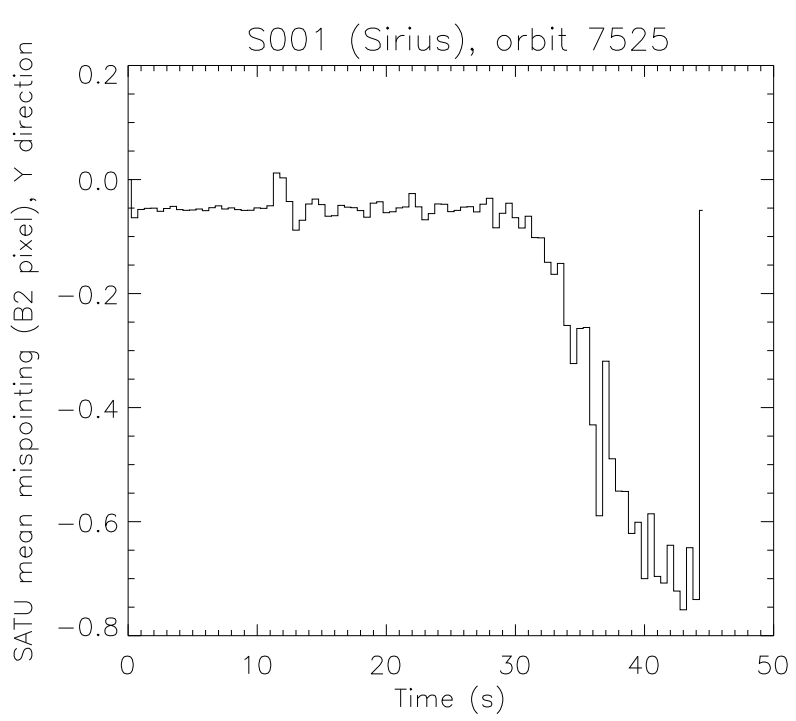

Fig. 10. Shifts from SATU for the whole occultation in the Y- (spatial) direction. The unit of mispointing is fraction of the vertical size of the B2 spectrometer pixel. The size of one GOMOS B2 spectrometer pixel is $27.0 \times 20.0 \mu \mathrm{m}$ (spatial $\times$ spectral).

correction of this modulation is performed for spectrometer A1 and A2 (after the cosmic ray correction). For spectrometer B1 and B2 the modulation is not corrected. There is a slow change in the amplitude of this modulation, which is monitored.

\subsection{Conversion into electrons}

A conversion of the ADU values into number of electrons is performed in each spatial band of the spectrometers A and $\mathrm{B}$ including also a non-linearity correction. This conversion needs the value of the CCD gain (in e/ADU) for each electronic chain and for each programmable gains (4 gains per spectrometer). The non-linearity correction of the electronic chain is performed in this processing step.

$D^{\mathrm{LIN}}=\left(D-d_{0}\right) f_{\text {nlin }}\left(D-d_{0}\right)$

$N^{\mathrm{RO}}=D^{\mathrm{LIN}} \times G$

Here $D$ is the spectrometer pixel value in ADU (after elimination of saturated, bad and cosmic ray pixels), $f_{\text {nlin }}$ is the non-linearity factor, $G$ is the electronic gain factor, $d_{0}$ is the off-set and $N^{\mathrm{RO}}$ is the number of electrons collected by the pixel. The non-linearity factor can be determined by using so-called linearity monitoring mode of GOMOS where the integration time can be specified between 0.25 to $10 \mathrm{~s}$. Originally it was measured on the ground in the instrument characterisation process.

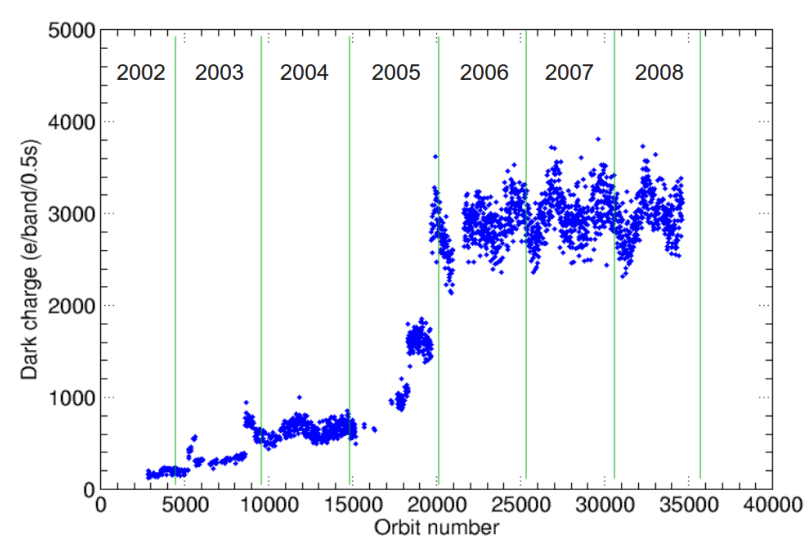

Fig. 11. Temporal dark charge evolution of a single binned CCD column. Expected long sensor warming and seasonal thermal variations are perfectly visible. Sharp variations of the dark charge level (e.g. around orbits $850,18500,20000$ ) are due to the occurrence of new "hot pixels".

\subsection{Dark charge}

During the Envisat flight a majority of the CCD pixels have become "hot", with a higher and variable dark charge. This degradation of the CCD's has been the main negative surprise in the GOMOS mission. The precipitation of protons is reason for this continuous increase of dark current.

In the absence of light, the level of dark charge is much higher than on the ground and it is highly variable from one pixel to the next (so-called DCNU, Dark Charge Non Uniformity). Also, its average level for one pixel may change, with a time scale that can vary from a few seconds to several hours. This phenomenon is called RTS (Random Telegraphic Signal). Therefore, a new observing strategy was set up. At each orbit, when Envisat is near the equator in deep night, GOMOS is pointed toward a dark area in the sky, collecting therefore only the dark charge on all CCDs. These measurements are used to correct all other occultations in the same orbit. Figure 11 shows the evolution of dark charge for individual CCD-column and Fig. 12 the increase of the mean dark charge with time for the spectrometer A2.

\subsection{Mirror reflectivity and vigneting}

The plane mirror of the SFA (Steering Front Assembly) is oriented in such a way that the line of sight is reflected in a fixed direction, along the telescope axis. The reflectivity of the mirror varies with wavelength and the angle of incidence, which is $\geq 25^{\circ}$. The incidence angle depends on the elevation and azimuth angles. Since the incidence angle varies by a few degrees during one occultation, it is important to correct this effect. Otherwise the transmission ratio of two star spectra measured with different incidence angles would be biased. A look-up-table has been built from Sirius 
observations with various azimuth and incidence angles. The variation of reflectivity is assumed to be a linear function of the angle of incidence.

At the extreme range of azimuth angles (negative angles), the plane mirror is vignetting (partially masking) a part of the collecting area for the IR spectrometer B. The degraded performance of the IR spectrometer at these azimuth angles (nominally from $-10^{\circ}$ to $-5^{\circ}$ ) is taken into account by a vignetting correction.

\subsection{Stray light and bright limb background}

The internal stray light is light coming from the region of FOV (Field Of View) limited by the slit but whose photons do not fall on their nominal position on the CCD. It is mainly generated by the grating as scattered light and it is most manifest as light from the star collected in the background bands. At present time, no correction of the internal stray light has been implemented.

The external stray light is light that makes its way through the slit, though its origin is outside the nominal FOV of the slit. There are mainly two sources of external stray light. One is the solar light scattered by some Envisat hardware into the baffle and optics of GOMOS. The other is coming from the sun-illuminated limb or nadir. The external stray light of solar origin does not go through the ozone layer and therefore contains some UV even at maximum ozone absorption wavelengths (near $255 \mathrm{~nm}$ ). At present time, no correction of the external stray light has been implemented. Still, geometrical computations are performed to characterise the illumination conditions of GOMOS, Envisat, and the tangent point of occultation at the limb at a reference altitude (the nominal value is $50 \mathrm{~km}$ ). The illumination condition is given in the flag stored in the Level $1 \mathrm{~b}$ product. This flag may be also used as a guide for the stray light contamination.

In bright limb occultations the background radiation falling on the central band needs to be estimated and subtracted from the measured central signal in order to get the star signal alone. This estimate is also used for photometers. The estimates of the upper and lower background are stored in the GOMOS Limb product.

Before the estimation, a flat field correction is applied to upper and lower bands. The sensitivity of each pixel is retrieved from a PRNU map (Pixel-to-pixel Response NonUniformity). The PRNU values of all pixels have been determined in-flight.

The processing software includes two different methods for estimating the background contribution inside the stellar band: (1) A linear interpolation between upper and lower bands. (2) An exponential interpolation (this is the method currently activated in the processing). The estimate for the central background is obtained as

$N_{\mathrm{C}}^{\mathrm{B}}=N_{\mathrm{C}}^{\mathrm{NST}} Q_{\mathrm{C}}$

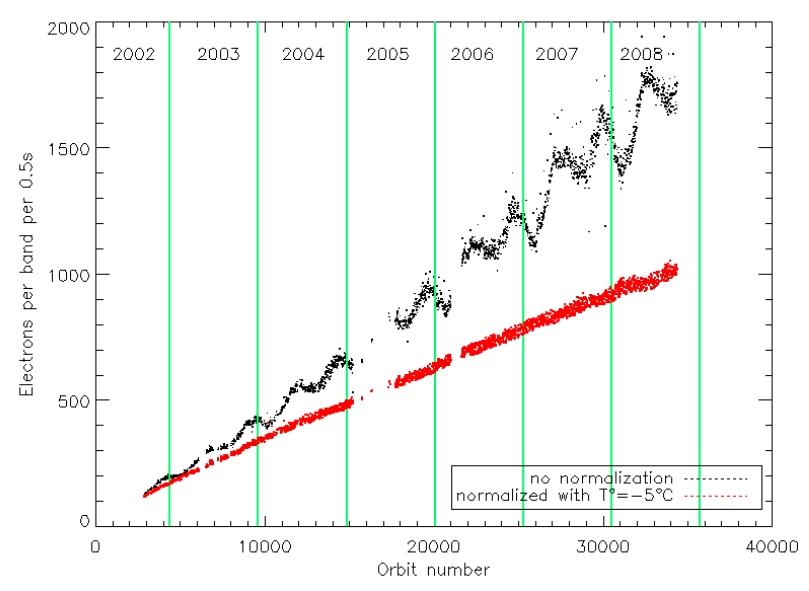

Fig. 12. Mean Dark Charge for spectrometer A2. The black curve shows seasonal variations due to the position of the sun and thus to the change of the temperature of the CCD. The red curve has been obtained by normalising the black curve at a reference temperature of $-5{ }^{\circ} \mathrm{C}$. Therefore, the red curve shows that an increase of Dark Charge independent of the temperature still exists.

where $N_{\mathrm{C}}^{\mathrm{NST}}$ is the background contribution for the central band from the method 1 or 2 and $Q_{\mathrm{C}}$ is PRNU averaged for the central band.

Once the central background $N_{\mathrm{C}}^{\mathrm{B}}$ is estimated, it is subtracted from the central band to get the stellar signal. This is not done in the full dark limb conditions for the spectrometer A. In full dark conditions the background is usually negligible and subtracting it would add the noise of the dark charge of the two background bands. There are, however, some atmospheric emissions lines that can be detected in GOMOS nighttime spectra. Examples are the famous auroral and airglow (green) line at $557.7 \mathrm{~nm}$ and the oxygen line around $630 \mathrm{~nm}$. In the GOMOS Level 2 processing the spectral range 627.9-630.0 nm (pixels 1215-1222) covering the oxygen line has been flagged and this area is not used in the retrieval.

For spectrometer $\mathrm{B}$, the background is not negligible even during the night. There are $\mathrm{O}_{2}$ emissions around $760 \mathrm{~nm}$ and $\mathrm{OH}$ emissions near $940 \mathrm{~nm}$. On the day side, the limb brightness is large. It saturates the spectrometers usually at altitudes lower than $26 \mathrm{~km}$ so that the background correction is no longer feasible. When any of the upper, central or lower band is saturated, the corresponding column is flagged and not used in the data processing.

\subsection{Star signal computation}

The stellar signal created by the background subtraction needs to be corrected for flat-fielding in order to get a valid estimation of the star spectrum. The nominal location of the star signal on the CCD, the SATU output data, the photometer engineering data and the PNRU are used in flat-fielding. 
The flat-fielding is most important for the spectrometers B1 and B2. During one spectrometer integration time, the image of the star spectrum is moving on the CCD due to refraction and residual pointing errors. Therefore several pixels with varying responses contribute to the measured signal. The signal at the band level will depend on the exact position on which the star spectrum is formed. This position is known from SATU data, at $100 \mathrm{~Hz}$ sampling rate. Coupled with a refraction model and with the instrument point spread function, the SATU information allows to estimate the current effective PRNU of the CCD pixels of the central band, which contains the star spectrum image. The scintillations measured from photometers data allow to take into account fast brightness variations of the star spectrum, for each position of the star spectrum at $100 \mathrm{~Hz}$ within a sample time $(0.5 \mathrm{~s})$.

If the star image in the slit deviates too much from the nominal central position, the slit may block a part of the signal. Because the position of the star image can be estimated from the star tracker, a look-up table can be used to recalibrate the signal as

$$
N^{\mathrm{S}}=\frac{\hat{N}^{\mathrm{S}}}{\bar{\tau}_{\text {slit }}}
$$

where the slit transmission is the calculated blocking factor. Figure 13 shows an example of the occulted star spectra (central band) at several tangent altitudes.

The Level $1 \mathrm{~b}$ processing for spectrometers is finalised (see, however, error analysis in Sect. 7) by calculating the so-called full transmission

$T=\frac{N^{\mathrm{S}}}{N^{\mathrm{REF}}}$

The full transmission is computed as the ratio of the estimated star spectrum to the reference spectrum of the current occultation. All the spectra used in this processing must be spectrally aligned before computation. The wavelength assignment of the star spectrum is re-sampled over the nominal spectral grid before the computation of the transmission. A reference spectrum of the star is measured at each occultation by averaging 10 measurements obtained above $120 \mathrm{~km}$. Examples of the Level $1 \mathrm{~b}$ transmissions can be found in Fig. 16 in the Level 2 processing.

\section{Photometer data processing}

The processing applied to the fast photometer data is to a large extent same as done for the spectrometers. Specific steps for photometers are unfolding and corrections for spikes. The background subtraction uses the estimated central background of the spectrometers as an input to remove the background contribution for the photometers.

Because of the 12 bits capacity of the on-board adder included in the photometer electronic chain, only the 12 least

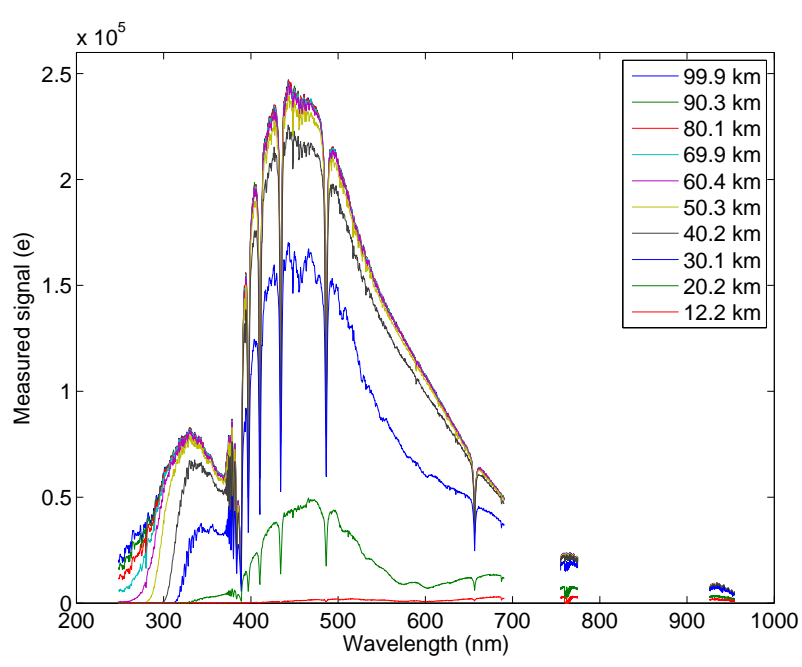

Fig. 13. Sirius spectrum measured through the atmosphere at several tangent altitudes.

significant bits are written in the GOMOS packets. In case of overflow, the analysis of the temporal series usually allows to rebuild the original signal (unfolding algorithm). The current unfolding algorithm compares the local variation of the signal to a threshold. However, in some circumstances (e.g. Sirius occultations with strong atmospheric scintillations), the real variability of the signal flux can exceed this threshold, leading to false overflow detection.

An incorrect unfolding of the photometer signal has a negative impact on the scintillation/dilution correction of the transmission spectra (Level 2 processing) and thus on the quality of the species retrieval. Discontinuities of the $\mathrm{NO}_{2}$ column density profiles have been observed at the altitudes of false reset corrections. The analysis of the processed occultations leads us to definitely avoid applying the unfolding process for the occultations of Sirius or in case of full dark limb condition where the overflow is assumed to be only occasional.

The photometer data are measured with a sampling rate of $1 \mathrm{kHz}$ and each sample corresponds to a time integration of the light intensity during one millisecond $(1 \mathrm{~ms})$. For each spectrometer measurement $(0.5 \mathrm{~s})$, there is consequently 500 photometer samples for each photometer. However, the last sample of each series of 500 is obtained with a time integration of $0.9 \mathrm{~ms}$ (instead of $1 \mathrm{~ms}$ ), thus producing a downward spike. This instrumental effect is corrected by dividing the value of the last sample in each series of 500 by 0.9 . An example of the photometer data is shown in Fig. 14. The figure shows the time delay effect explained in Fig. 3. The red light from a given structure is detected first when using setting occultations. The vertical separation chromatic lag varies (exponentially) from $1 \mathrm{~m}$ at $45 \mathrm{~km}$ to $10 \mathrm{~m}$ at $30 \mathrm{~km}$ to $60 \mathrm{~m}$ at $20 \mathrm{~km}$ and $300 \mathrm{~m}$ at $10 \mathrm{~km}$ The related time delay is obtained by dividing by the vertical velocity of ENVISAT (less than 


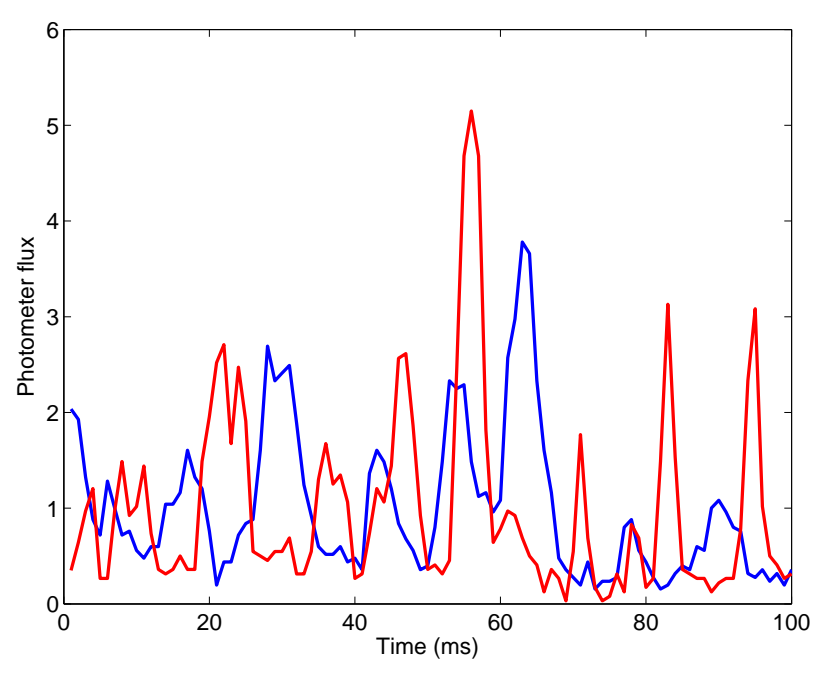

Fig. 14. Blue and red photometer signals. Both signals have been normalised by dividing by the mean. In the horizontal axis time is the occultation time measured from the altitude of $26 \mathrm{~km}$ ( $35 \mathrm{~s}$ since the beginning of the occultation). The obliquity of the occultation is 3.9. Some peaks show clearly the time delay effect between the red and blue photometers.

$3.4 \mathrm{~km} / \mathrm{s}$ ). The time delay is then from $3 \mathrm{~ms}$ at $30 \mathrm{~km}$ and $88 \mathrm{~ms}$ at $10 \mathrm{~km}$.

\section{Error analysis}

All the Level $1 \mathrm{~b}$ products are accompanied by error estimates. These estimates are calculated assuming that there is no modelling errors and assuming a normal Gaussian error statistics. The pixel data are assumed to be independent on each other. We ignore all correlations between pixels. In the following the main error contributions for the main products are reviewed.

The error on any signal coming from a CCD is

$\Delta N=\sqrt{N+\Delta_{\mathrm{dc}}^{2}+R_{\mathrm{ro}}^{2}+\frac{G^{2}}{12}}$

The first component under the square-root is the photon noise, the second $\left(\Delta_{\mathrm{dc}}\right)$ is the noise associated with the dark charge removal, the third one ( $R$ ro) is the read-out noise and the last one is the quantisation noise.

The error on the background has been estimated by

$\Delta_{b}=\sqrt{\left|B_{\text {est }}\right|}$

where $B_{\text {est }}$ is the estimate of background signal in the central band.

The error on the estimated stellar signal is

$\Delta N=\sqrt{N+\Delta_{\mathrm{dc}}^{2}+R_{\mathrm{ro}}^{2}+\frac{G^{2}}{12}+\Delta_{\mathrm{sl}}^{2}+\Delta_{\mathrm{b}}^{2}}$ where $\Delta_{\mathrm{sl}}$ is the error associated to the subtraction of stray light, and $\Delta_{\mathrm{b}}$ is the error associated to the subtraction of background. At present, $\Delta_{\mathrm{sl}}$ is set to zero because the stray light correction is not activated.

The error on the reference spectrum is given by

$\Delta N_{\text {ref }}=\frac{1}{p} \sqrt{\sum_{j=1}^{p} \Delta N_{j}^{2}}$

where $p=10$ is the number of measurements averaged.

The error on the transmission is

$\Delta T=T \sqrt{\left(\frac{\Delta N}{N}\right)^{2}+\left(\frac{\Delta N_{\text {ref }}}{N_{\text {ref }}}\right)^{2}}$

The error of the photometer signal is dominated by the shot noise, and the estimate is taken as the square root of the signal.

All these error estimation formulas have been validated by simulations and by in-flight statistical analysis of measurements.

\section{Introduction to GOMOS geophysical retrieval}

The GOMOS Level $1 \mathrm{~b}$ products that are used in the GOMOS Level 2 processing are:

- transmission data $\left(T^{\mathrm{obs}}\right)$;

- photometer data $\left(I_{\mathrm{pho}}^{\mathrm{obs}}\right)$;

- geolocation data $(\ell(\lambda, t))$;

- a priori atmospheric data $\left(\rho_{\text {air }}(\bar{r}), \mathrm{T}(\bar{r})\right)$.

Main data are the transmission spectra at different tangent heights. Photometric data from the two fast photometers are used to correct the transmissions from the scintillation effects. Photometric data are also used to retrieve a high resolution temperature profiles of the atmosphere. Geolocation and the a priori atmospheric data are necessary information in dealing with the refractive effects and at the initialising stage of the retrieval.

In the GOMOS Level 2 processing the data set processed is the measurements from one star occultation at a time. Even if some occultations would probe the same atmospheric region at successive orbits these occultations are treated separately. Therefore, the possibility to carry out some kind of atmospheric tomography by GOMOS has not been considered in the ESA Level 2 processing. In the present GOMOS ground processing limb spectra from Level $1 \mathrm{~b}$ are not used for atmospheric retrieval but this possibility is under development.

The geophysical retrieval strategy in the Level 2 data processing assumes that a measured transmission can be taken as a product of two transmissions

$T^{\mathrm{obs}}=T_{\text {ref }} T_{\text {ext }}$ 
The transmission $T_{\text {ref }}$ is due to refractive effects and the transmission $T_{\text {ext }}$ is due to absorption and scattering processes in the atmosphere. The Level 2 processing aims first to estimate the refractive part using the fast photometer data and the geolocation data, and then to remove it from the measured transmission (for details, see Sofieva et al., 2009). The remaining transmission can then be connected to the atmospheric constituent densities. This transmission can be written as:

$T_{\mathrm{ext}}=e^{-\tau}$

where the optical depth $\tau$ is given by

$\tau(\lambda)=\sum_{j} \int_{\ell} \sigma_{j}(\lambda, T(\bar{r}(s))) \rho_{j}(\bar{r}(s)) d s$

In principle there is no obstacle to an inversion approach where we use directly Eqs. (17) and (18) to retrieve the constituent profiles. This approach can be called one-step inversion. In practice, the problem is the size of the input data and the number of the estimated parameters. The one-step approach is being studied in the GOMOS processing development but it is not used in the present GOMOS processing.

In the Level 2 data processing strategy the following simplifications have been adopted in order to bring the inversion problem into a more manageable form (see Sihvola, 1994):

1. Separate UVIS and IR spectrometer retrievals. Separate $\mathrm{B} 1$ and $\mathrm{B} 2$ spectrometers retrievals.

2. Decouple spectral and vertical inversion problems as far as possible.

The first simplification cuts the number of data points from 2336 of the original problem to 1416 points in the spectrometer $\mathrm{A}, 420$ points in the spectrometer B1 and and 500 points in the spectrometer B2. The second simplification allow us to perform the retrieval in a sequential way (see Fig. 15). We need still to decide if the spectral inversion or the vertical inversion is performed first. If the spectral inversion is performed first, horizontal column densities of different constituents $N_{j}(z)$ are calculated first as the intermediate products. If the vertical inversion is performed first, profiles of the absorption coefficients $k(\lambda, z)$ are the intermediate products. In the GOMOS ground segment the spectral inversion is performed first because it leads to a rapid compression in the data volumes processed.

The separation of spectral and vertical inversions discussed above leads to some inaccuracies in the inversion modelling but these are counteracted by performing an iteration loop over the spectral and vertical inversion.

In addition to the refractive effects, there are two additional measurement features that must be taken into account in the retrieval. The first one is the finite measurement time $(0.5 \mathrm{~s})$ of GOMOS. During this time the tangent point altitude changes considerably (remember Fig. 7). The second feature

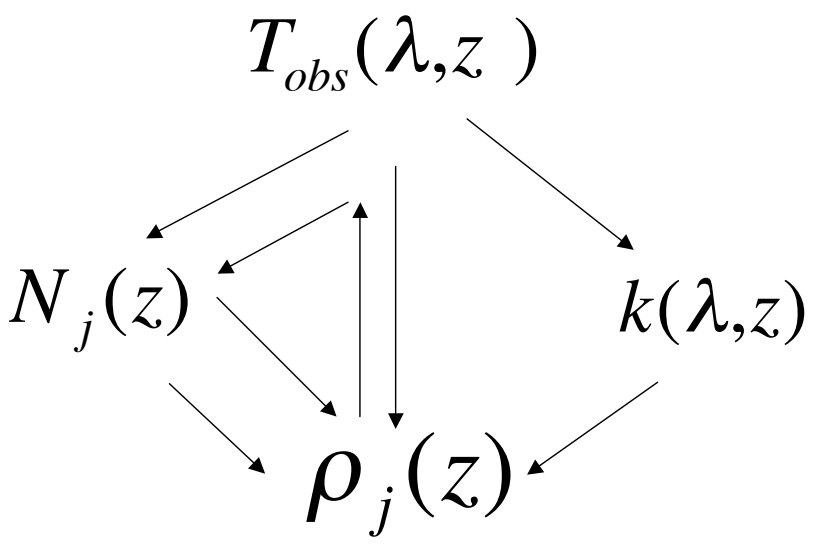

Fig. 15. Alternative ways to approach the GOMOS retrieval. From the observed transmissions $T_{\text {obs }}$, at different altitudes and wavelengths, we can directly retrieve vertical profiles of different constituents $\rho_{j}$ by one-step inversion. Alternatively, we can first retrieve either horizontal columns for various extinction processes $N_{j}$ or absorption coefficients $k$ and then proceed to vertical profiles. The GOMOS operational processing uses the path $T_{\mathrm{obs}} \rightarrow N_{j} \rightarrow$ $\rho_{j}$ with iteration over the path. For more complete discussion, see Kyrölä et al. (1993).

is the finite spectral resolution of the instrument. This means that we cannot simply use the cross sections as such in the inversion but we must take the instrumental resolution into account.

\section{Refractive effects}

The scintillation and dilution corrections (see Dalaudier et al., 2001) are based on the assumption that the refractive transmission can be split into two independent terms

$T_{\text {ref }}(t)=T_{\text {dil }}(t) T_{\text {sci }}(t)$

where $T_{\text {dil }}$ represents the dilution component and $T_{\text {sci }}$ represents the effect of scintillations, assumed to be free of direct chromatic effect.

$T_{\text {sci }}$ is estimated using the signal of the fast photometer that has the highest signal to noise ratio. The principle is to minimise extinction effects in the photometer bands. The photometer with less extinction is usually the red photometer. The estimation of this term is made with the assumption that all high frequency fluctuations in the photometer signal (if we exclude noise fluctuations) are due to scintillations and that fluctuations due to structures in vertical profiles of absorbing constituents affect only the low frequency part of the signal. This assumption is justified by the fact that the absorption depends on the integrated density along the line of sight, while the dilution is sensitive to the second vertical derivative of the integrated density. 
The mean dilution is approximated by using the so-called phase screen approximation where the effect of the extended atmosphere on the light wave is replaced by that of a virtual phase screen located at the tangent point. The refractive bending takes place only at the screen. With this approximation the mean dilution can be written simply as

$$
T_{\mathrm{dil}}(z, \lambda)=\frac{1}{1+L \frac{d \delta(z, \lambda)}{d z}}
$$

where $L$ is the distance from the tangent point (screen) to the satellite and $\delta$ is the refractive angle of the ray. In the Level 2 processing the refractive angle is taken from the ray tracing calculation performed in the Level $1 \mathrm{~b}$ processing.

The scintillation transmission is estimated by

$$
T_{\mathrm{sci}}(t)=\frac{I_{\mathrm{ph}}(t)}{\bar{I}_{\mathrm{ph}}(t)}
$$

where the numerator is the photometer signal and the denominator is the smoothed photometer signal. The smoothing is performed by the Hanning filter (Press et al., 1992) over an adjustable time interval. In vertical distance the default value is about $3 \mathrm{~km}$. The combined effect due to dilution and scintillations during one integration time of the spectrum $(0.5 \mathrm{~s})$ is now given by

$$
\bar{T}_{\text {ref }}=\frac{1}{\Delta t} \int T_{\text {ref }}(t) d t=\frac{1}{\Delta t} \int_{\Delta t} T_{\mathrm{dil}}(t) T_{\mathrm{sci}}(t) d t
$$

The transmission due to absorption and scattering can then be calculated by dividing the observed transmission by the estimated refractive part

$T_{\mathrm{ext}}^{\mathrm{obs}}=\frac{T^{\mathrm{obs}}}{\bar{T}_{\text {ref }}}$

It is important to note that, at this stage, we have transmission corresponding to tangent altitudes depending on wavelength. The chromatic effect is taken into account in the mean dilution term. The chromatic effect, which is neglected in scintillation correction, is the intensity normalisation resulting from difference in "duration" of the same structure when viewed at different wavelengths. In other words, the integration time in Eq. (22) is also wavelength dependent.

There are two fundamental restrictions of the scintillation correction algorithm. The algorithm does not fully correct so-called strong scintillations where the light rays cross and it is not generally able to correct scintillations from isotropic fluctuations in the atmosphere. The correction for isotropic scintillations works only if the FOV of the instrument is in the orbital plane. For more information about scintillation effects see Sofieva et al. (2009).

Because of chromatic refraction at any given time GOMOS receives stellar light from different altitudes. GOMOS data processing includes two methods to handle this non-uniqueness of the tangent height, The first method presented below modifies the observed transmissions. The other method in Sect. 11.2 modifies the transmission model.

We calculate the tangent points corresponding to each pixel of each spectrum and then calculate the transmission for given tangent altitudes by performing linear interpolations between two acquisitions

$\widetilde{T}_{\mathrm{ext}}^{\mathrm{obs}}\left(z_{j}, \lambda\right)=r T_{\mathrm{ext}}^{\mathrm{obs}}\left(z_{j}, \lambda\right)+(1-r) T_{\mathrm{ext}}^{\mathrm{obs}}\left(z_{j}+1, \lambda\right)$

$\widetilde{T}_{\mathrm{ext}}^{\mathrm{obs}}\left(z_{j}, \lambda\right)=(1-r) T_{\mathrm{ext}}^{\mathrm{obs}}\left(z_{j}, \lambda\right)+r T_{\mathrm{ext}}^{\mathrm{obs}}\left(z_{j-1}, \lambda\right)$

The first alternative is applied for wavelengths $\lambda$ smaller or equal to the fixed reference wavelength and the second alternative to the rest. The coefficient $r$ is the interpolation coefficient:

$r= \pm \frac{z_{j}\left(\lambda_{\text {ref }}\right)-z_{j \pm 1}(\lambda)}{z_{j}(\lambda)-z_{j \pm 1}(\lambda)}$

This approach represents the first alternative method to correct the chromatic refraction effects. The second alternative is presented in connection with the transmission modelling.

An example of the Level $1 \mathrm{~b}$ and Level 2 refraction corrected transmission is shown in Fig. 16. Figure 17 shows the refraction transmission i.e. the ratio of Level $1 \mathrm{~b}$ and Level 2 transmissions (see Eq. 23). At high altitudes it tends to unit value but at low altitudes shown in figure the refraction transmission varies strongly with altitude and wavelength. Figure 18 shows the signal-to-noise ratio for the refraction corrected transmission. Note the strong variations as a function of altitude and wavelength.

\section{High resolution temperature from photometers}

In addition being used for the scintillation correction, the photometers data provide information about small scale density structures in the atmosphere. A high resolution temperature profile (HRTP) can be derived from time the delay of the two photometers. Due to the variation of the index of refraction with wavelength, a light beam from an occulted star is more bent in the blue part of the spectrum than in the red part. For a given tangent altitude, the red beam reaches GOMOS before the blue beam because GOMOS measures only setting stars (see Fig. 3).

The computation of the time delay gives information on the bending angle which is related to the density and temperature profile in the atmosphere. This method allows us to derive a high resolution temperature profile with a vertical resolution of 100-200 $\mathrm{m}$.

The algorithm is divided in three main parts:

1. Computation of the chromatic time delay between the two photometers.

2. Determination of the refraction angle. 


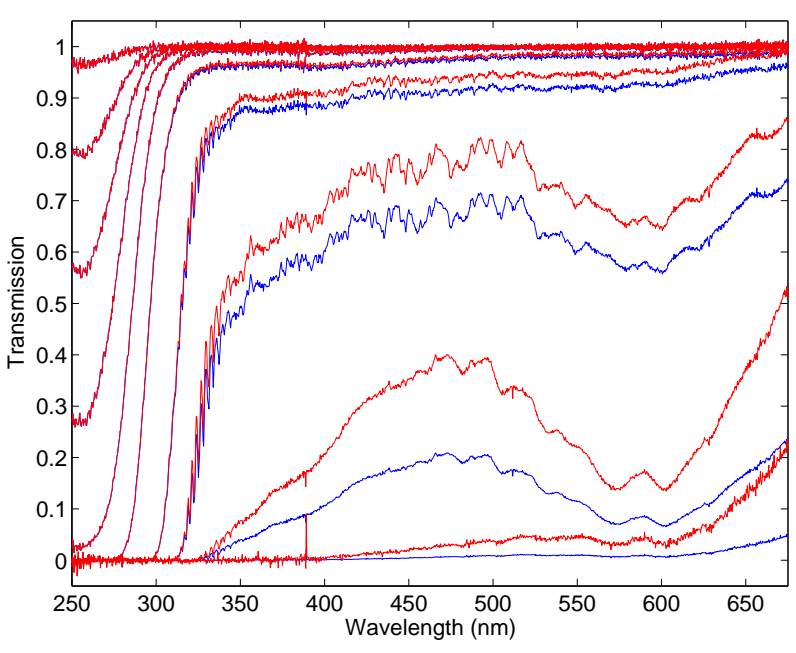

Fig. 16. Level $1 \mathrm{~b}$ transmissions (blue) and refraction corrected transmissions (red) at various altitudes. The altitudes and the star are the same as in Fig. 13 and Fig. 18.

3. Determination of the density, pressure and temperature profiles.

The time delay is computed at $40 \mathrm{~Hz}$ corresponding to a vertical sampling of $85 \mathrm{~m}$ at maximum. This means that 20 time delay values are computed during each $0.5 \mathrm{~s}$ spectrometer measurement. The time delay is computed by searching such a time shift between the blue and the red signal that gives the maximum correlation between the two signals taken in a time window corresponding to a vertical movement of the tangent altitude of $250 \mathrm{~m}$.

The difference in the refractive angle between the central wavelengths of the blue and the red photometers is obtained from the time delay $\Delta t$ as

$\delta_{\text {blue }}-\delta_{\text {red }}=\frac{v_{\mathrm{z}} \Delta t}{L}$

where $L$ is the distance between GOMOS and the limb and $v_{\mathrm{Z}}$ the projection of the satellite velocity on the vertical axis at the tangent point.

The refractive angle is directly proportional to the refractivity $v-1$ and it is obtained with a linear transformation

$\delta_{\text {blue }}=\frac{\left(\delta_{\text {blue }}-\delta_{\text {red }}\right) \nu_{\text {blue }}}{\left(\nu_{\text {blue }}-v_{\text {red }}\right)}=\left(\delta_{\text {blue }}-\delta_{\text {red }}\right)\left(\frac{\Delta v}{v}\right)^{-1}$

The coefficient $\Delta v / v=0.011$ depends on the exact band pass of the photometers.

Once the refraction angle is obtained as a function of the impact parameter (at $40 \mathrm{~Hz}$ ), the profile of refractivity, directly proportional to the atmospheric density, is obtained by inverting the following Abel integral:

$n\left(h_{\text {blue }}\right)=\frac{1}{\pi} \int_{h_{\text {blue }}}^{\infty} \frac{\delta_{\text {blue }}(h)}{\sqrt{(R+h)^{2}-\left(R+h_{\text {blue }}\right)^{2}}} d h$

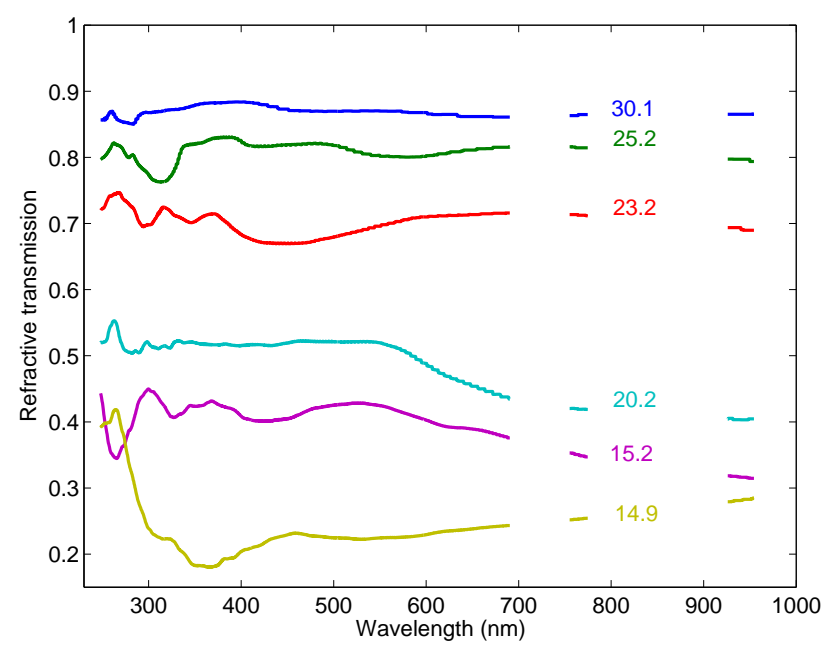

Fig. 17. Refractive transmission at altitudes $14-16 \mathrm{~km}$. The occultation is the same as in Fig. 16.

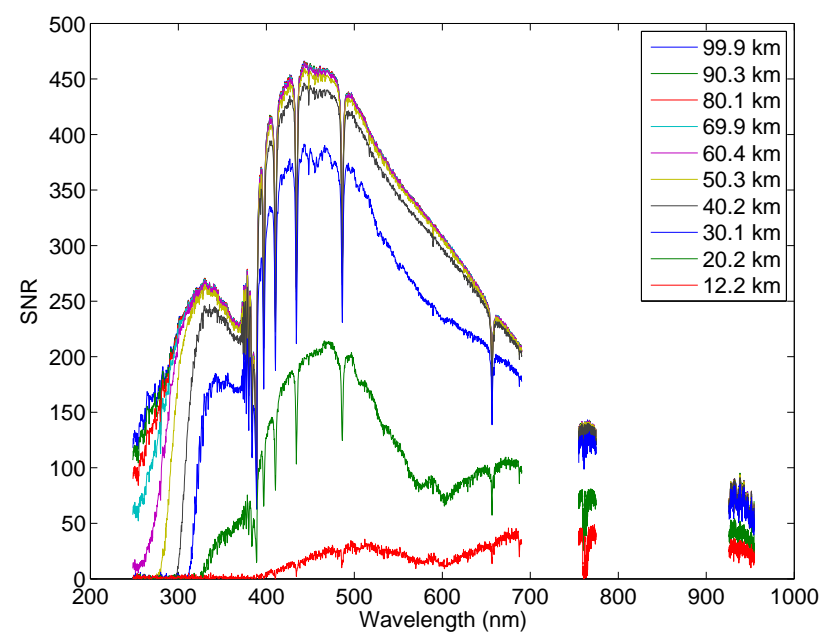

Fig. 18. Level 2 transmission signal-to-noise ratio. The occultation is the same as in Fig. 16.

where $h_{\text {blue }}$ is the impact parameter and $R$ the Earth radius. The inversion is done downwards starting from the top of the high resolution profile (around $35-40 \mathrm{~km}$ ) and using the model atmospheric profile at the tangent point above this altitude. Once the density profile is obtained, the temperature profile is computed using the hydrostatic equation.

\section{Transmission model developments}

If we assume GOMOS to be nearly ideally imaging instrument and the source to be a point source, the model transmission can be written as the following two-dimensional integral: 


$$
\bar{T}(\lambda, t)=\frac{1}{\Delta t} \iint T_{\mathrm{ext}}\left(\lambda^{\prime}, \ell\left(t, \lambda^{\prime}\right)\right) W\left(\lambda, \lambda^{\prime}, t\right) d t d \lambda^{\prime}
$$

where $W$ is the instrument point spread function. $W$ is time dependent because during the integration time the stellar image wanders in the slit plane and its image on the CCD plane does the same. This causes some spectral smearing.

In the following we show how the model transmission is developed so that it can be used effectively in the data inversion (for details, see Sihvola, 1994).

\subsection{Effective cross section method}

Temperature dependent cross sections couple the spectral and spatial dimensions of the problem. According to our strategy, we aim at factorizing the problem into spectral and vertical inversion problems. This can be achieved by using the effective cross section method. We write the extinction as

$$
\begin{aligned}
\tau(\lambda, \ell) & =\sum_{j} \int_{\ell} \rho_{j}(s) \sigma_{j}(\lambda, \mathrm{T}(s)) d s \\
& =\sum_{j} \sigma_{j}^{\text {eff }}(\lambda, \ell) N_{j}
\end{aligned}
$$

where $N_{j}$ is the horizontal column density of the species $j$

$$
N_{j}=\int_{\ell} \rho_{j}(z(s)) d s
$$

and $\sigma^{\text {eff }}$ is the effective cross-section of species $j$

$\sigma_{j}^{\text {eff }}(\lambda, \ell)=\frac{\int_{\ell} \sigma_{j}(\lambda, \mathrm{T}(s)) \rho_{j}(s) d s}{N_{j}}$

The use of the effective cross-section separates the inversion problem into spectral and spatial parts. The two parts are, however, coupled together by the unknown effective cross sections. An iterative loop over spectral and vertical inversion is needed to take this into account. Initially we can use the tangent point temperature in Eq. (33). This relieves the cross sections from the integration and the effective cross section is equal to the normal cross section (at tangent point temperature). After the first vertical inversion the effective cross section is along the LOS averaged cross section where the local constituent density acts as a weight.

\subsection{Spectral and temporal integration}

The other model simplification aims to eliminate the spectral and temporal integrations in the model function Eq. (30). The need for this simplification is computationally efficiency. Using a perturbation technique we can recover the exponential form of the model transmission. The detailed calculations are not shown here (see Sihvola, 1994; GOMOS ESL, 1998) but the final result is

$\bar{T}(\lambda, t)=e^{-\widehat{\tau}}$ where the modified optical extinction is ( $h$ 's being the tangent heights):

$$
\begin{aligned}
\widehat{\tau}(\lambda)= & -\sum_{j} \widetilde{\sigma}_{j}(\lambda) \bar{N}_{j}-\frac{1}{2} \sum_{i j} B_{i j}(\lambda) \bar{N}_{i} \bar{N}_{j} \\
& +\left(z(\lambda)-z\left(\lambda_{\text {ref }}\right)\right) \sum_{j} \widetilde{\sigma}_{j}(\lambda) \frac{d \bar{N}_{j}}{d z} \\
& -\frac{(\Delta z)^{2}}{24}\left(\sum_{j} \tilde{\sigma}_{j}(\lambda) \frac{d \bar{N}_{j}}{d z}\right)^{2}
\end{aligned}
$$

where $\Delta z$ is the vertical coverage of the measurement at the tangent point. The convoluted cross sections are defined by

$\tilde{\sigma}_{j}(\lambda)=\int W\left(\lambda^{\prime}-\lambda\right) \sigma_{j}\left(\lambda^{\prime}\right) d \lambda^{\prime}$

and the coefficients $B_{i j}$ are coming from the convolution of cross-section correlations

$B_{i j}(\lambda)=\int W\left(\lambda^{\prime}-\lambda\right) \sigma_{i}\left(\lambda^{\prime}\right) \sigma_{j}\left(\lambda^{\prime}\right) d \lambda^{\prime}-\sigma_{i}(\lambda) \sigma_{j}(\lambda)$

Note that the cross sections here are the effective cross sections. The unknown instantaneous horizontal column densities are now replaced by the averaged densities

$\bar{N}_{j}=\frac{1}{\Delta t} \int N_{j}(t) d t$

The derivates of the horizontal column densities are calculated during the spectral-vertical inversion iteration loop only.

The transmission model Eqs. (34-35) includes the chromatic refraction effect, the spectral convolution by the instrument and the time integration effect. Obviously all these effects are taken into account in an approximate way only.

The original inversion problem is now separated into UVIS and IR parts and into the spectral and vertical inversion problems. In the spectral problem the averaged horizontal column densities Eq. (38) are retrieved by fitting the reduced observed transmission Eq. (23) with the model Eqs. (34-35). The vertical inversion part is given by Eq. (32) with the vertical profiles $\rho_{j}(z)$ as the unknowns. This implies that the instantaneous horizontal column densities $N_{j}$ need to be related to the averaged horizontal column densities of Eq. (38).

\section{Spectral inversion}

\subsection{Cross sections}

The kernels of the spectral inversion problem Eq. (31) are the cross sections (see Fig. 19). The simulations performed before and after the GOMOS launch have shown that in the UVIS spectral region $\mathrm{O}_{3}, \mathrm{NO}_{2}, \mathrm{NO}_{3}$, aerosols and neutral density can be retrieved from all stars observed by GOMOS. Some other minor constituents like sodium and OClO can be 


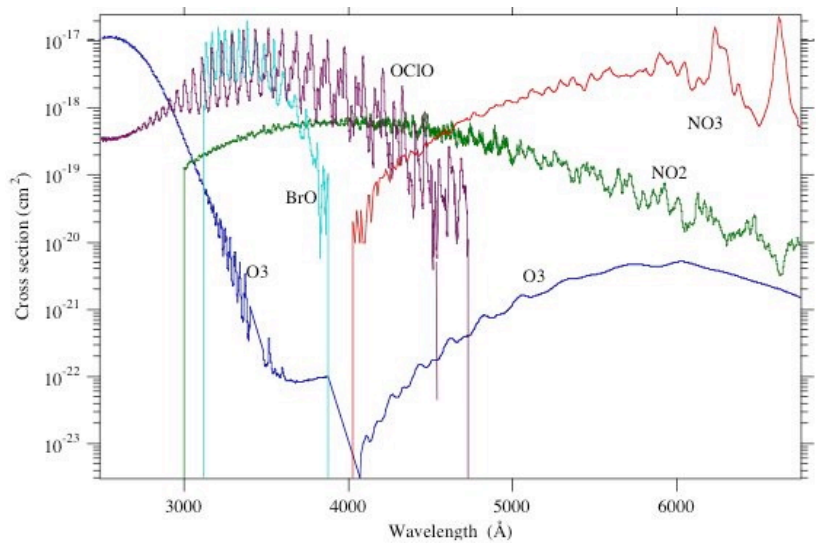

Fig. 19. Cross sections in the UV-visible domain.

retrieved only by averaging many occultations (see Fussen et al., 2006; Tétard et al., 2009; Fussen et al., 2010 ). These are not considered in the ESA GOMOS processing. In the IR $\mathrm{O}_{2}$ and $\mathrm{H}_{2} \mathrm{O}$ bands contain smoothly varying extinction from Rayleigh and aerosol scattering and from ozone absorption but these are not objects of retrieval.

Except for the neutral density and partly for aerosols, the cross sections are obtained from laboratory measurements. For all the GOMOS retrieved constituents there are several alternative cross section available (see http:// www.atmosphere.mpg.de/spectral-atlas-mainz). There are no cross sections measured directly by the GOMOS instrument. The selection of the cross sections used in the GOMOS processing can be found from http://envisat.esa.int/ handbooks/gomos/.

The scattering cross-sections can be approached analytically. The Rayleigh cross-section needed for the extinction by neutral air scattering has the following form:

$\sigma_{\mathrm{R}}(\lambda)=1.06 \frac{32 \pi^{3}}{3} \frac{(n(\lambda)-1)^{2}}{\lambda^{4} N_{\mathrm{stp}}^{2}}$

The factor 1.06 is the depolarisation factor for air. The index of refraction $n(\lambda)$ follows the Edlen's law. $N_{\text {stp }}$ is the air number density at sea level.

The specification of the aerosol scattering cross section is much more difficult. The aerosol content varies all the time in the atmosphere. In the retrieval we can either fix a certain best guess aerosol cross section or we can try to define a flexible aerosol cross section (actually aerosol extinction) with unknown model parameters retrieved from GOMOS data. Both these approaches have been used in the GOMOS Level 2 processing. In early software versions we used the Angström's formula ( $b$ constant near 1)

$\sigma_{a}(\lambda)=\frac{\sigma_{0}}{\lambda^{b}}$
The present software version 5 uses a more flexible polynomial expansion

$\tau(\lambda)=\int_{\ell} \beta(z(s), \lambda) d s=c_{0}+c_{1} \Delta \lambda+\ldots$

where $\Delta \lambda=\lambda-\lambda_{\text {ref }}\left(\lambda_{\text {ref }}=500 \mathrm{~nm}\right)$ and the coefficients $c_{i}$ are unknowns to be determined.

The order of the aerosol polynomial in Eq. (41) depends on the aerosol state of the atmosphere. In case of high volcanic activity (e.g., the post-Pinatubo period 1991-1993), a broad maximum of $\beta(\lambda)$ can be observed in the visible range and therefore at least a quadratic polynomial is required for a correct description. During background conditions, the spectral dependence of the aerosol extinction coefficient exhibits mostly a monotonic decrease versus wavelength. The polynomial order should be kept as low as possible due to the non-orthogonality of the aerosol optical thickness dependence with respect to other constituents having a similar cross section (like Rayleigh scattering by air). Ozone is not strongly coupled with aerosol due to its strong spectral signature.

\subsection{UVIS spectral inversion}

In the spectral inversion the observed refraction corrected transmissions are fitted by the model transmission Eq. (34) where the horizontal column densities are the unknowns. The GOMOS spectral inversion is based on the method that is spectrally global, uses absolute cross sections, takes a nonlinear approach and assumes no explicit a priori information (see Kyrölä et al., 1993; Sihvola, 1994).

The estimation of column densities is based on the standard maximum likelihood method. We aim to minimise the so-called cost function between the data and the model. Data noise is assumed to be Gaussian (see Kyrölä et al., 1993) and therefore the suitable cost function has the following quadratic form:

$S(\boldsymbol{N})=\left(\overline{\boldsymbol{T}}(\boldsymbol{N})-\boldsymbol{T}_{\mathrm{ext}}^{\mathrm{obs}}\right)^{\boldsymbol{T}} \mathbf{C}^{-1}\left(\overline{\boldsymbol{T}}(\boldsymbol{N})-\boldsymbol{T}_{\mathrm{ext}}^{\mathrm{obs}}\right)$

The unknown vector $\boldsymbol{N}$ includes all the relevant horizontal constituent densities at a given altitude. The constituents covered are: $\mathrm{O}_{3}, \mathrm{NO}_{2}, \mathrm{NO}_{3}$, neutral air and three coefficients for aerosols. The observed transmission is given by Eq. (23) or Eqs. (24-26). The matrix $\mathbf{C}$ is the covariance matrix of the transmission data from Level $1 \mathrm{~b}$ and modified by the refraction correction Eq. (23). The minimisation is done by using the Levenberg-Marquardt algorithm (see Press et al., 1992). The algorithm also produces an estimate for the covariance matrix of column densities. This gives gas-gas correlations.

The retrieval process described above has been modified after the GOMOS launch as an response to difficulties in the neutral density retrieval and to larger than expected effects from scintillations. The retrieval of the neutral density often leads to a large bias with respect to the values from ECMWF. Therefore, it has been decided to fix the neutral density to 
the value given by ECMWF for altitudes below $1 \mathrm{hPa}$ and to MSIS90 above. The Rayleigh scattering contribution is removed from the observed transmissions before the spectral inversion.

In $20-40 \mathrm{~km}$ chromatic scintillations, caused by isotropic turbulence, create perturbations in GOMOS transmission spectra. These lead to unrealistic oscillations in the vertical profiles of horizontal column densities of $\mathrm{NO}_{2}$ and $\mathrm{NO}_{3}$. The scintillation correction step presented in Sect. 9 is unable to remove these scintillations from the transmission data. In order to improve the retrieval, a variant of DOAS named GDI (Global DOAS Iterative) is applied separately to $\mathrm{NO}_{2}$ and $\mathrm{NO}_{3}$ retrieval.

In the GDI Hauchecorne et al. (2005) a species is artificially separated into two virtual species $\mathrm{X}_{S}$ and $\mathrm{X}_{D}$ with their respective cross-sections

$\sigma_{S}(\lambda)+\sigma_{D}(\lambda)=\sigma(\lambda)$

The spectral inversion is performed in two phases. The first Levenberg-Marquardt fit is applied with $X_{S}=X_{0}$ and $X_{D}$ as a free parameter together with all other species that we want to retrieve. The fit gives a first value $X_{D}^{(1)}$. The second fit is applied with $X_{S}=X_{D}^{(1)}$. A second value $X_{D}^{(2)}$ is obtained. The process is iterated until the maximum number of iterations is performed or until a given convergence criterion is reached.

Example of the spectral inversion residuals are shown in Fig. 20. Generally the residuals are small except for altitudes where scintillations cannot be corrected accurately enough.

\subsection{IR spectrometer spectral inversion}

The IR spectrometer measures the densities of $\mathrm{O}_{2}$ in 755$774 \mathrm{~nm}$ and $\mathrm{H}_{2} \mathrm{O}$ in $926-954 \mathrm{~nm}$. An example of the IR transmissions in $755-774 \mathrm{~nm}$ is shown in Fig. 21. These two bands are treated separately. Due to the physics of the problem, the individual absorption lines are very narrow and saturated, the apparent cross sections change with the integrated densities and they can no longer be considered as only wavelength dependent. The calculation of the transmission model is computationally very demanding. Therefore, it is difficult to use the same direct inversion approach as for the UVIS spectrometer data.

A new algorithm has been developed for the $\mathrm{O}_{2}$ and $\mathrm{H}_{2} \mathrm{O}$ retrieval. The method uses reference transmission spectra $T_{\bmod }(\lambda, N)$ calculated for different column densities $(N)$ of $\mathrm{O}_{2}$ and $\mathrm{H}_{2} \mathrm{O}$. These reference transmissions depend slightly on pressure. In order to take this into account the calculation of transmissions is performed by using a forward model with a standard atmospheric profile. Several such calculations are done for different atmospheric states like tropical, mid-latitude and subarctic. The calculations are made in steps of $1 \mathrm{~km}$ altitude from 0 to $100 \mathrm{~km}$, with the highest possible wavelength resolution allowed by the HITRAN data base and the radiative transfer code LBLRTM (see http:

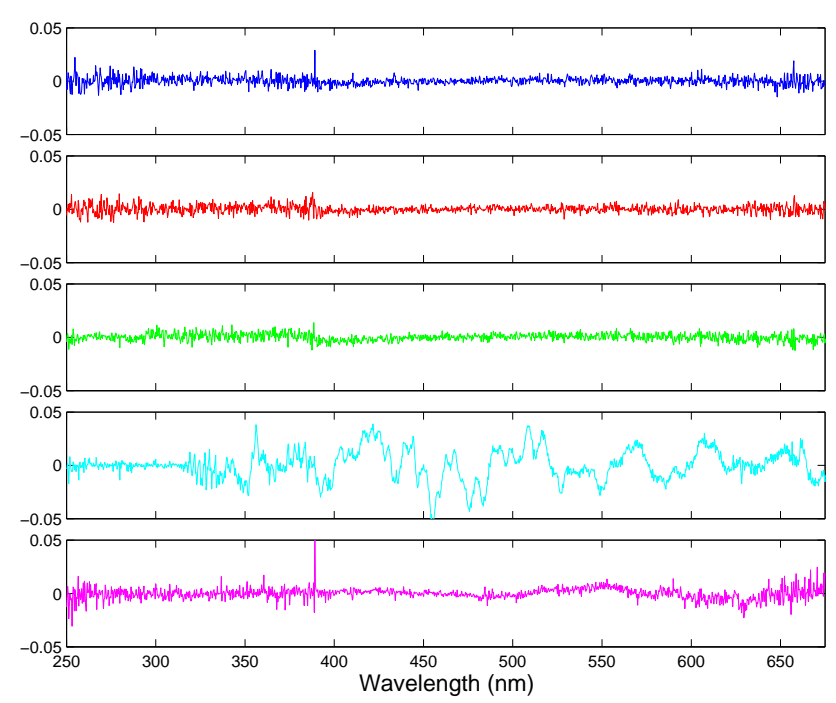

Fig. 20. Residuals (unit-less) between observed and modelled transmissions at altitudes 12 (bottom panel), 30, 50, 90 and $100 \mathrm{~km}$ (top panel). The disturbances from scintillations are evident at $30 \mathrm{~km}$.

//rtweb.aer.com/lblrtm.html). Transmissions are convoluted with the instrumental function of GOMOS and integrated over each spectral wavelength interval $(0.046 \mathrm{~nm}$ for B 1 and $0.056 \mathrm{~nm}$ for B2).

The retrieval method fits a function

$\log T_{\text {obs }}=a \log \left(T_{\text {mod }}(\lambda, N)\right)+\frac{b}{\lambda}+c$

to the observed transmissions. The last two terms in Eq. (44) are for the fitting of the background. By varying the model function or by varying the altitude where the model function is calculated we aim to minimise the difference $a-1$. Due to its nature, this method has been called "comparative method".

Actually, for the $\mathrm{O}_{2}$ band at $760 \mathrm{~nm}$, there is a small absorption by ozone in the Wulf bands. Therefore, the observed transmission $T_{\mathrm{obs}}$ is first corrected from the extinction of ozone, as determined from the spectral inversion of spectrometer A. In addition, the Rayleigh extinction by air (fixed with ECMWF and MSISE-90), and the aerosol extinction extrapolated at the wavelength of spectrometers B1 and B2 are also computed for a further correction of $T_{\mathrm{obs}}$, before the comparison with the tables of $T_{\bmod }$.

The values of coefficients $b$ and $c$ may represent a deviation of the wavelength dependence of the aerosol extinction far away from the reference wavelength $(500 \mathrm{~nm})$. However, one should be cautious since the dilution and scintillations may change quite severely the level of the continuum. 


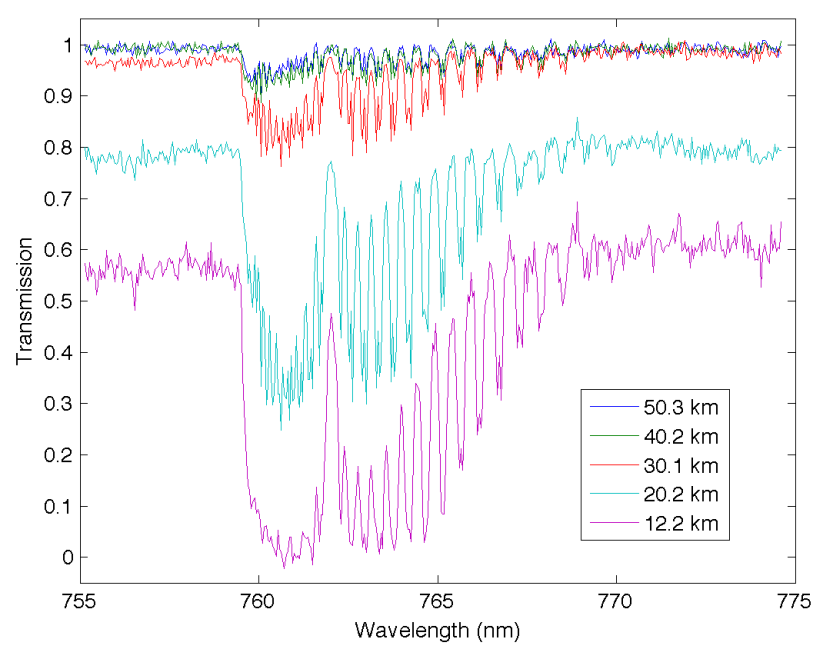

Fig. 21. Level 2 refraction corrected transmissions in the $\mathrm{O}_{2}$ IRband. The occultation is the same as in Fig. 16.

\section{Vertical inversion}

The GOMOS vertical inversion aims to find a vertical profile $\rho(z)$ that fulfils

$N\left(z_{t}\right)=\int \rho(z(s)) d s$

where $N$ is any of the horizontal column densities retrieved in the spectral inversion. In principle, the vertical inversion should be performed together for all constituents retrieved already simultaneously in the spectral inversion. The coupling between different column densities is mediated by the covariance matrix from the spectral inversion. In the present version of the GOMOS, vertical inversion the off-diagonal constituent-constituent covariances are, however, neglected and the vertical profile for each constituent is retrieved independently.

The problem Eq. (45) is discretised by dividing the atmosphere into layers. Layers are set in such a way that a tangent altitude is always in the middle of a layer. The number of layers is set equal to the number of measurements in the occultation processed. The resulting problem is then a readily solvable linear inversion problem. By the triangular nature of the kernel matrix the inversion can be done using the socalled onion peeling method.

The vertical inversion method used in the GOMOS data processing makes an attempt to create continuous constituent profiles instead of the layer structure of the onion peeling technique. We approximate the local densities to be linear functions of altitude between two successive GOMOS measurements (other approaches have been discussed in Sihvola, 1994.)

$\rho(z)=\frac{\left(z_{j-1}-z\right) \rho\left(z_{j}\right)+\left(z-z_{j}\right) \rho\left(z_{j-1}\right)}{z_{j-1}-z_{j}}$
The horizontal column density values used as data are the result of an integration in time and then should be adapted to the "instantaneous" expression that has been derived (i.e. the linear system is only valid for instantaneous horizontal column densities). To pass from integrated to instantaneous data we use Eq. (38) and expand $N_{j}(t)$ around the integration time mid-point as a Taylor expansion. The result up to the second order is

$\bar{N}_{j}=N_{j}+\frac{(\Delta t)^{2}}{24} \frac{\partial^{2} N_{j}}{\partial t^{2}}$

After these developments the vertical inversion problem consists of solving the following linear system:

$\bar{N}=\mathbf{K} \rho$

where $\mathbf{K}$ is a relatively complicated kernel matrix. This matrix equation can be solved by standard methods.

In the case of GOMOS, the inversion presented above produces vertical profiles accompanied with unphysical oscillations. In order to remove these, we have introduced a smoothness requirement to the retrieved profiles. The smoothing is implemented by using the Tikhonov regularisation method. Traditionally the amount of smoothing is assessed by optimising the trade-off between the smoothness and the vertical resolution (see Rodgers, 2000). In the GOMOS retrieval a different approach has been taken. As the need for smoothing varies strongly depending on the stellar properties and the measurement geometry (short and long occultations), the traditional approach would result in different resolution for each occultation. Therefore, it was decided to choose an approach that keeps the vertical resolution for each occultation constant (at given altitude) despite the varying measurement conditions. This was done by applying socalled target resolution form of the Tikhonov regularisation (Sofieva et al., 2004).

The target resolution Tikhonov solution of Eq. (48) is given by

$\hat{\boldsymbol{\rho}}=\left(\mathbf{K}^{T} \mathbf{K}+\alpha \mathbf{H}^{T} \mathbf{H}\right)^{-1} \mathbf{K}^{T} \boldsymbol{N}$

where the regularisation matrix $\mathbf{H}$ is

$\mathbf{H}=\operatorname{diag}\left[\frac{1}{h_{i}^{2}}\right]\left[\begin{array}{lllll}0 & 0 & 0 & \ldots & 0 \\ 1 & -2 & 1 & \ldots & 0 \\ \ldots & . . & \ldots & \ldots & \ldots \\ 0 & \ldots & 1 & -2 & 1 \\ 0 & 0 & \ldots & 0 & 0\end{array}\right]$

Here $\left[\frac{1}{h_{i}^{2}}\right]$ is shorthand to dividing all matrix elements by the square of the local altitude difference. The covariance matrix is also produced. The covariances provide the vertical correlations of errors.

The regularisation parameter $\alpha$ in Eq. (49) was selected in such a way that the retrieved profiles have the desired target resolution. For ozone the target resolution was selected to be 
$2 \mathrm{~km}$ below $30 \mathrm{~km}$ and $3 \mathrm{~km}$ above $40 \mathrm{~km}$ (with smooth transition between 30 and $40 \mathrm{~km}$ ). For $\mathrm{NO}_{2}, \mathrm{NO}_{3}$, aerosols, $\mathrm{O}_{2}$, and $\mathrm{H}_{2} \mathrm{O}$ the target resolution was put to $4 \mathrm{~km}$. By applying this target resolution method the GOMOS profiles are easier to use in validation, time-series, climatologies, etc.

With the vertical inversion we have produced trace gas profiles. These new profiles are injected to the calculation of the effective cross-sections and the spectral and vertical inversion are carried out again. It has been shown that this iterative process improves significantly the final results. Therefore, it is routinely applied (at least once and at the maximum twice). The overall GOMOS Level 2 architecture is shown in Fig. 22 and the products in Figs. 23-24.

\section{GOMOS algorithm development}

The GOMOS data processing has undergone many changes since the launch in 2002. Changes have been initiated by the validation work and continuous investigations on the retrieval quality. These issues are discussed in more detail in other articles of this special issue.

The most important changes are (for a complete list, see the monthly GOMOS report from http://earth.esa.int/pcs/ envisat/gomos/reports/):

- Calibration of the dark charge takes place in each orbit in order to counteract the increase of dark current noise in the GOMOS CCDs.

- Modulation correction of CCD signals.

- DOAS-type inversion for $\mathrm{NO}_{2}$ and $\mathrm{NO}_{3}$ to counteract perturbations from isotropic scintillations.

- Neutral density fixed to the values given by ECMWF and MSIS90. The GOMOS atmospheric product (GAP) is, therefore, not produced.

- Aerosol model changed from the Angström formula to the second order polynomial model.

- Tikhonov regularisation in the vertical inversion to smooth oscillations in vertical profiles.

The next software version 6 will include the following improvements:

- Full covariance matrix in the spectral inversion. This takes into account the spectral correlations from isotropic scintillations. The inclusion of the full covariance provides stabilises the spectral inversion and improves the error estimates of vertical profiles. See Sofieva et al. (2010).

- HRTP algorithm is enhanced by the computation of effective wavelengths of the photometer signals. The sensitivity to outliers has been reduced.

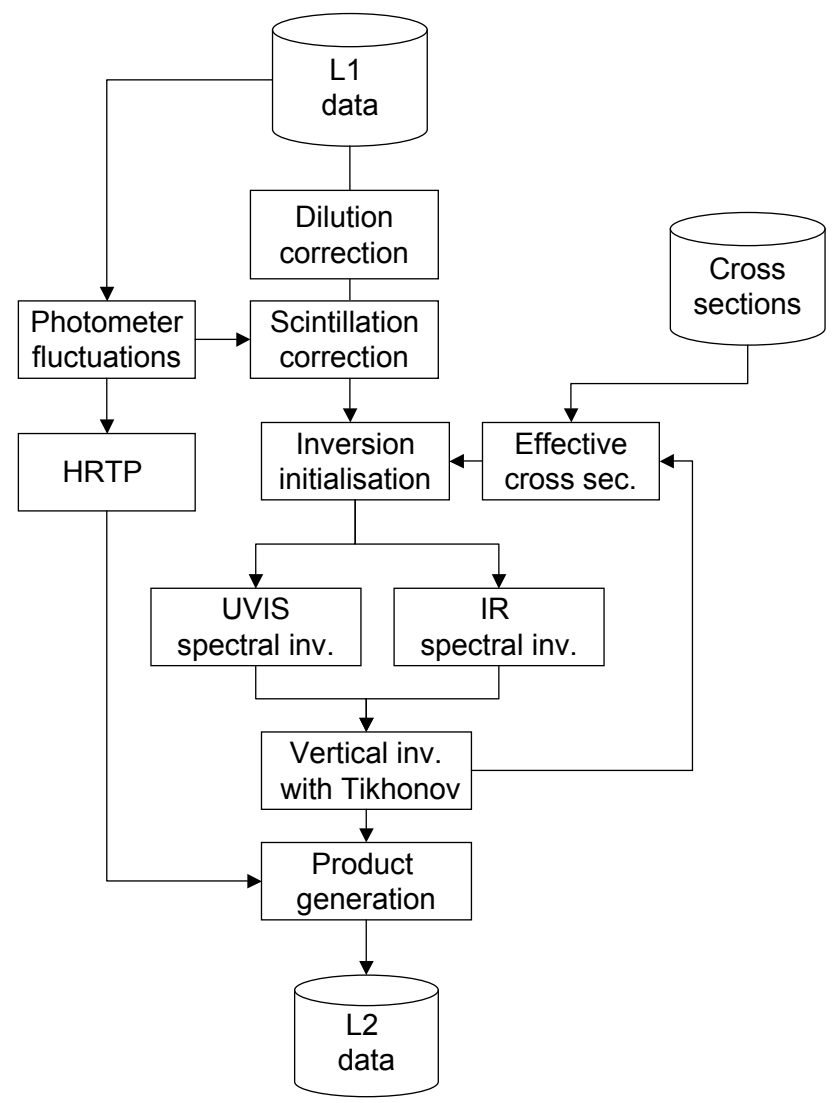

Fig. 22. GOMOS Level 2 processing architecture.

- Calibration procedures have been refined. Studies on inflight data have shown that the response inside one pixel is not uniform. Therefore the PRNU correction takes this intra sensitivity into account. These changes improve specially the $\mathrm{H}_{2} \mathrm{O}$ retrievals and ozone retrievals from UV-poor (cool and weak) stars.

The overall development of the GOMOS algorithms continues. Several improvements are under investigation. Most important are

- Retrieval from GOMOS limb products. This requires corrections for straylight. Preliminary results for ozone retrieval look promising.

- Aerosol model development.

The GOMOS Level $1 \mathrm{~b}$ and Level 2 data processing contains quite an extensive collection of processing modules that presumably take all the major physical effects into account. An ongoing activity tries to map and estimate the effects from the (hopefully) minor processes so far neglected. The modelling errors from the omitted processes have been discussed in Tamminen et al. (2010) of this special issue. 

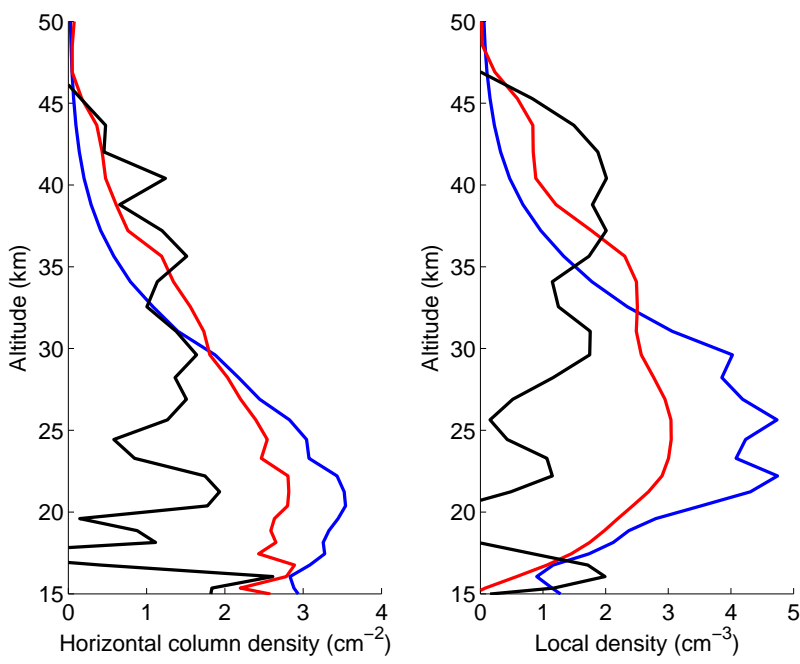

Fig. 23. GOMOS Level 2 horizontal columns (left panel) and vertical profiles (right panel). $\mathrm{O}_{3}$ (blue line ), $\mathrm{NO}_{2}$ (red line) and $\mathrm{NO}_{3}$ (black line). Column scales/profile scales are for $\mathrm{O}_{3}: 10^{20} / 10^{12}$, $\mathrm{NO}_{2}: 10^{17} / 10^{9}$ and $\mathrm{NO}_{3}: 10^{15} / 10^{7}$.

\section{Access to GOMOS data}

GOMOS Level $1 \mathrm{~b}$ and Level 2 data are freely available via ESA website http://eopi.esa.int/esa/esa?cmd= submission\&aoname=cat1. GOMOS data can be ingested by the Enviview and BEAT software downloadable at http: //envisat.esa.int/resources/softwaretools/. A comprehensive documentation for GOMOS instrument and data can be found at http://envisat.esa.int/handbooks/gomos/. The GOMOS ATBD document can be found at http://envisat.esa. int/instruments/gomos/atbd/. GOMOS product disclaimers are available at http://envisat.esa.int/handbooks/availability/ disclaimers/ GOMOS regular daily and monthly reports are available at http://earth.esa.int/pcs/envisat/gomos/reports/.

GOMOS has two Level 1b products and two Level 2 products. Table 2 provides some basic information about these products.

\section{Alternative retrieval methods}

The operational GOMOS algorithms and processing routines have been developed since 1988 . For many retrieval or processing steps there are more than one alternative. The GOMOS operational software includes at many stages alternative algorithms and some of these have already been discussed in this paper. A reason to select a certain way to proceed has usually been based on computational effectiveness. The following list gives some alternative ways to handle GOMOS data:

- Optimal estimation Rodgers (2000). The GOMOS operational processing does not use a priori profiles for
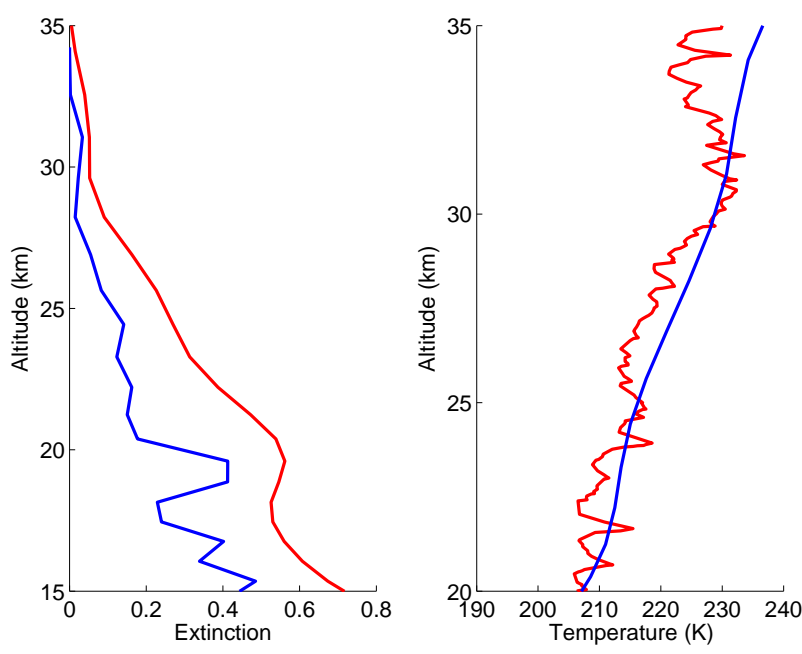

Fig. 24. GOMOS Level 2 aerosol (left panel) products and the High resolution Temperature Profile (HRTP) (right panel). Left panel: GOMOS Level 2 aerosol horizontal extinction (blue line, unit-less) and local aerosol extinction (red line, unit $=1 \mathrm{~km}$ ). Right panel: HRTP (red line) and ECMWF temperature (blue line).

Table 2. GOMOS products. The sizes refer to short (40s) - long occultation (150 s). All products include geolocation data, error estimates and processing flags. The flags are essential data to find bad data values.

\begin{tabular}{lrl}
\hline Product & Typical size & Key contents \\
\hline GOM_TRA & $3.5-15 \mathrm{MB}$ & transmissions, photometer data \\
GOM_LIM & $2-10 \mathrm{MB}$ & $\begin{array}{l}\text { upper and lower band data } \\
\text { refraction corrected transmission, } \\
\text { fOM_EXT }\end{array}$ \\
$2-10 \mathrm{MB}$ model \\
GOM_NL & $70-400 \mathrm{~KB}$ & $\begin{array}{l}\text { horizontal column densities and re- } \\
\text { lated gas-gas covariances, vertical } \\
\text { local densities and related layer- } \\
\text { layer covariances (limited), HRTP, } \\
\chi^{2} \text {-values }\end{array}$ \\
\hline
\end{tabular}

constituents. The ECMWF neutral density is eliminated from data as an $100 \%$ known contributor. This could also be done using a priori approach.

- DOAS-inversion. A partial DOAS retrieval is included in the GOMOS spectral inversion.

- One-step inversion. This possibility has been investigated in Vanhellemont et al. (2004). The method is further developed in the ESA AERGOM project 20092010.

- Vertical smoothing. As an alternative to the Tikhonov regularisation in the profile retrieval, the transmissions can be smoothed in the vertical direction before the spectral inversion. This has been studied in Fussen et al. (2005). 
- Vertical smoothing and DOAS. The method of Renard et al. (2008) combines DOAS and the vertical smoothing in order to reduce oscillations from scintillations.

- Averaged transmissions. Instead of retrieving atmospheric data from single occultation, we can first sum transmissions from several nearby (time and location) occultations and then retrieve from the combined transmission. This is a way to find constituents with very weak fingerprints in spectra. See the article by Fussen et al. (2010) in this special issue.

- The Markov chain Monte Carlo method (MCMC) provides more complete information about atmospheric parameters than the normal maximum likelihood method. The MCMC method is still too slow for operational GOMOS retrieval. For more information, see Tamminen and Kyrölä (2001) and Tamminen et al. (2010).

Many of these alternatives have been tested and compared with operational results using processing prototypes available at various scientific institutes. A limited version of FMI's GomLab processor can be found at http://public.me. com/erkki.kyrola:FinGoodsGui.

\section{Conclusions}

In this paper we have presented the Level $1 \mathrm{~b}$ and Level 2 processing algorithms for the ESA GOMOS ground segment. These algorithms were developed mainly during 1988-1998 using simulated data for verification. After real GOMOS measurements became available, three main surprises we encountered. The first surprise was the sensitivity of the GOMOS CCD's to particle precipitation, which has led to a steady increase of noise in data. The more frequent dark current measurements have helped to fight back the deteriorating of retrievals. The decreasing $S / N$ ratio affects the retrieval quality and especially the ozone retrieval using the weak and cool stars above $35 \mathrm{~km}$ suffers.

The second surprise was the importance of isotropic scintillations in data. GOMOS was prepared to correct for anisotropic scintillations by photometer measurements and this has worked fine but for isotropic scintillations the method does not work. The implementation of GDI in the spectral inversion and the Tikhonov smoothing in the vertical inversion have helped to minimise the effects from isotropic scintillations. The upcoming change to the full covariance spectral inversion will further alleviate this problem.

The third surprise concerns the daytime measurements. The inaccurate removal of the scattered light from the occultation signals have held back the use of day occultations. The main problem is the background removal stage where even small relative errors in the background field easily contaminate the underlying stellar signal. Actually more progress is now achieved from retrievals based on the background term itself.
Presently ozone, $\mathrm{NO}_{2} \mathrm{NO}_{3}$, aerosol and HRTP results from GOMOS are of good quality with respect to their statistical properties. The IR-spectrometer products $\mathrm{H}_{2} \mathrm{O}$ and $\mathrm{O}_{2}$ are expected to improve from the new processor version 6 . The GOMOS ozone, $\mathrm{NO}_{2} \mathrm{NO}_{3}$, and aerosol results have already been used to create climatologies and time series in Hauchecorne et al. (2005), Kyrölä et al. (2006), Vanhellemont et al. (2010) and Kyrölä et al. (2010).

Acknowledgements. The GOMOS Level 2 processing scheme is a product of many years and many people. The following people have participated in the development: FMI: E. Kyrölä, G. W. Leppelmeier, L. Oikarinen (deceased in 2002), E. Sihvola, J. Tamminen, V. Sofieva; Service d'Aeronomie: du CNRS: P. Benet, J. L. Bertaux, E. Chassefière, F. Dalaudier, A. Hauchecorne, J.C. Lebrun, M. Martic, B. Théodore; IASB: D. Fussen, P. Simon, M. Van Roozendael; ACRI: A. Mangin, M. Guirlet, O. Fanton d'Andon, G. Barrot, L. Blanot; ESA: C. Readings, J. Langen, G. Levrini, T. Wehr, A. Popescu, F. Spiero, R. Koopman, T. Fehr, L. Saavedra de Miguel; EADS-Astrium: R. Fraisse. In particular, the team wishes to thank Odile Fanton d'Andon for her enthusiasm, encouragement, and leadership, all of which have been essential in obtaining a coherent result from such a diverse group.

Edited by: W. T. Sturges

\section{References}

Bertaux, J. L., Megie, G., Widemann, T., Chassefiere, E., Pellinen, R., Kyrölä, E., Korpela, S., and Simon, P.: Monitoring of Ozone Trend by Stellar Occultations: The GOMOS Instrument, Adv. Space Res., 11, 237-242, 1991

Bertaux, J. L., Kyrölä, E., and Wehr, T.: Stellar Occultation Technique for Atmospheric Ozone Monitoring: GOMOS on Envisat, Earth Observation Quarterly, 67, 17-20, 2000.

Bertaux, J. L., Hauchecorne, A., Dalaudier, F., Cot, C., Kyrölä, E., Fussen, D., Tamminen, J., Leppelmeier, G. W., Sofieva, V., Hassinen, S., d'Andon, O. F., Barrot, G., Mangin, A., Théodore, B., Guirlet, M., Korablev, O., Snoeij, P., Koopman, R., and Fraisse, R.: First results on GOMOS/Envisat, Adv. Space Res., 33, 1029 1035, 2004.

Bertaux, J. L., Kyrölä, E., Fussen, D., Hauchecorne, A., Dalaudier, F., Sofieva, V., Tamminen, J., Vanhellemont, F., Fanton d'Andon, O., Barrot, G., Mangin, A., Blanot, L., Lebrun, J. C., Pérot, K., Fehr, T., Saavedra, L., and Fraisse, R.: Global ozone monitoring by occultation of stars: an overview of GOMOS measurements on ENVISAT, Atmos. Chem. Phys. Discuss., 10, 9917-10076, doi:10.5194/acpd-10-9917-2010, 2010.

Bovensmann, H., Burrows, J. P., Buchwitz, M., Frerick, J., Noël, S., Rozanov, V. V., Chance, K. V., and Goede, A. P. H.: SCIAMACHY: Mission Objectives and Measurement Modes, J. Atmos. Sci., 56, 127-150, doi:10.1175/1520-0469(1999) 056〈0127:SMOAMM $\rangle$ 2.0.CO;2, 1999.

Chu, W. P., McCormick, M. P., Lenoble, J., Brogniez, C., and Pruvost, P.: SAGE II inversion algorithm, J. Geophys. Res., 94, 8339-8351, 1989.

Dalaudier, F., Kan, V., and Gurvich, A. S.: Chromatic refraction with global ozone monitoring by occultation of stars. I. De- 
scription and scintillation correction, Appl. Optics, 40, 866-877, 2001.

Elliot, J. L.: Stellar occultation studies of the solar system, Ann. Rev. Astron. Astrophys., 17, 445-475, 1979.

ESA: Envisat-GOMOS, An instrument for global atmospheric ozone monitoring, vol. SP-1244, European Space Agency, 2001.

Fussen, D., Vanhellemont, F., Bingen, C., Kyrölä, B., Tamminen, J., Sofieva, V., Hassinen, S., Seppälä, A., Verronen, P. T., Bertaux, J. L., Hauchecorne, A., Dalaudier, F., D'Andon, O. F., Barrot, G., Mangin, A., Theodore, B., Guirlet, M., Renard, J. B., Fraisse, R., Snoeij, P., Koopman, R., and Saavedra, L.: Autoregressive smoothing of GOMOS transmittances, Adv. Space Res., 36, 899-905, doi:10.1016/j.asr.2005.04.007, 2005.

Fussen, D., Vanhellemont, F., Dodion, J., Bingen, C., Mateshvili, N., Daerden, F., Fonteyn, D., Errera, Q., Chabrillat, S., Kyrölä, E., Tamminen, J., Sofieva, V., Hauchecorne, A., Dalaudier, F., Bertaux, J., Renard, J.-B., Fraisse, R., Fanton d'Andon, O., Barrot, G., Guirlet, M., Mangin, A., Théodore, B., , Snoeij, P., and Saavedra, L.: A global OClO stratospheric layer discovered in GOMOS stellar occultation measurements, Geophys. Res. Lett., 33, L13815, doi:10.1029/2006GL026406, 2006.

Fussen, D., Vanhellemont, F., Tétard, C., Mateshvili, N., Dekemper, E., Loodts, N., Bingen, C., Kyrölä, E., Tamminen, J., Sofieva, V., Hauchecorne, A., Dalaudier, F., Bertaux, J.-L., Barrot, G., Blanot, L., Fanton d'Andon, O., Fehr, T., Saavedra, L., Yuan, T., and She, C.-Y.: A global climatology of the mesospheric sodium layer from GOMOS data during the 2002-2008 period, Atmos. Chem. Phys., 10, 9225-9236, doi:10.5194/acp-10-92252010, 2010.

Glaccum, W., Lucke, R. L., Bevilacqua, R. M., Shettle, E. P., Hornstein, J. S., Chen, D. T., Lumpe, J. D., Krigman, S. S., Debrestian, D. J., Fromm, M. D., Dalaudier, F., Chassefière, E., Deniel, C., Randall, C. E., Rusch, D. W., Olivero, J. J., Brogniez, C., Lenoble, J., and Kremer, R.: The Polar Ozone and Aerosol Measurement instrument, J. Geophys. Res., 101, 14479-14488, 1996.

GOMOS ESL: GOMOS Detailed Processing Model (DPM), ESA, 1998.

Hauchecorne, A., Bertaux, J.-L., Dalaudier, F., Cot, C., Lebrun, J.C., Bekki, S., Marchand, M., Kyrölä, E., Tamminen, J., Sofieva, V., Fussen, D., Vanhellemont, F., Fanton d'Andon, O., Barrot, G., Mangin, A., Théodore, B., Guirlet, M., Snoeij, P., Koopman, R., Saavedra de Miguel, L., Fraisse, R., and Renard, J.B.: First simultaneous global measurements of nighttime stratospheric $\mathrm{NO}_{2}$ and $\mathrm{NO}_{3}$ observed by Global Ozone Monitoring by Occultation of Stars (GOMOS)/Envisat in 2003, J. Geophys. Res., 110, D18301, doi:10.1029/2004JD005711, 2005.

Hays, R. G. and Roble, P. B.: Stellar spectra and atmospheric composition, J. Atmos. Sci., 25, 1141-1153, 1968.

Karttunen, H., Kröger, P., Oja, H., Poutanen, M., and Donner, K. J. (eds.): Fundamental Astronomy, 4th edition, Springer-Verlag, Berlin, Germany, 2003.

Kyrölä, E., Sihvola, E., Kotivuori, Y., Tikka, M., Tuomi, T., and Haario, H.: Inverse Theory for Occultation Measurements, 1, Spectral Inversion, J. Geophys. Res., 98, 7367-7381, 1993.

Kyrölä, E., Tamminen, J., Leppelmeier, G. W., Sofieva, V., Hassinen, S., Bertaux, J.-L., Hauchecorne, A., Dalaudier, F., Cot, C., Korablev, O., d'Andon, O. F., Barrot, G., Mangin, A., Theodore, B., Guirlet, M., Etanchaud, F., Snoeij, P., Koopman, R., Saave- dra, L., Fraisse, R., Fussen, D., and Vanhellemont, F.: GOMOS on Envisat: An overview, Adv. Space Res., 33, 1020-1028, 2004.

Kyrölä, E., Tamminen, J., Leppelmeier, G. W., Sofieva, V., Hassinen, S., Seppälä, A., Verronen, P. T., Bertaux, J.-L., Hauchecorne, A., Dalaudier, F., Fussen, D., Vanhellemont, F., d'Andon, O. F., Barrot, G., Mangin, A., Theodore, B., Guirlet, M., Koopman, R., Saavedra, L., Snoeij, P., and Fehr, T.: Nighttime ozone profiles in the stratosphere and mesosphere by the Global Ozone Monitoring by Occultation of Stars on Envisat, J. Geophys. Res., 111, D24306, doi:10.1029/2006JD007193, 2006.

Kyrölä, E., Tamminen, J., Sofieva, V., Bertaux, J. L., Hauchecorne, A., Dalaudier, F., Fussen, D., Vanhellemont, F., Fanton d'Andon, O., Barrot, G., Guirlet, M., Fehr, T., and Saavedra de Miguel, L.: GOMOS $\mathrm{O}_{3}, \mathrm{NO}_{2}$, and $\mathrm{NO}_{3}$ observations in 2002-2008, Atmos. Chem. Phys., 10, 7723-7738, doi:10.5194/acp-10-77232010, 2010.

Llewellyn, E., Lloyd, N. D., Degenstein, D. A., Gattinger, R. L., Petelina, S. V., Bourassa, A. E., Wiensz, J. T., Ivanov, E. V., McDade, I. C., Solheim, B. H., McConnell, J. C., Haley, C. S., von Savigny, C., Sioris, C. E., McLinden, C. A., Griffioen, E., Kaminski, J., Evans, W. F. J., Puckrin, E., Strong, K., Wehrle, V., Hum, R. H., Kendall, D. J. W., Matsushita, J., Murtagh, D. P., Brohede, S., Stegman, J., Witt, G., Barnes, G., Payne, W. F., Piche, L., Smith, K., Warshaw, G., Deslauniers, D. L., Marchand, P., Richardson, E. H., King, R. A., Wevers, I., McCreath, W., Kyrola, E., Oikarinen, L., Leppelmeier, G. W., Auvinen, H., Megie, G., Hauchecorne, A., Lefevre, F., de La Noe, J., Ricaud, P., Frisk, U., Sjoberg, F., von Scheele, F., and Nordh, L.: The OSIRIS instrument on the Odin spacecraft, Can. J. Phys., 82, 411-422, doi:10.1139/p04-005, 2004.

Meijer, Y. J., Swart, D. P. J., Allaart, M., Andersen, S. B., Bodeker, G., Boyd, Braathena, G., Calisesia, Y., Claude, H., Dorokhov, V., von der Gathen, P., Gil, M., Godin-Beekmann, S., Goutail, F., Hansen, G., Karpetchko, A., Keckhut, P., Kelder, H. M., Koelemeijer, R., Kois, B., Koopman, R. M., Lambert, J.-C., Leblanc, T., McDermid, I. S., Pal, S., Kopp, G., Schets, H., Stubi, R., Suortti, T., Visconti, G., and Yela, M.: Pole-to-pole validation of ENVISAT/GOMOS ozone profiles using data from groundbased and balloon-sonde measurements, J. Geophys. Res., 109, D23305, doi:10.1029/2004JD004834, 2004.

Pérot, K., Hauchecorne, A., Montmessin, F., Bertaux, J.-L., Blanot, L., Dalaudier, F., Fussen, D., and Kyrölä, E.: First climatology of polar mesospheric clouds from GOMOS/ENVISAT stellar occultation instrument, Atmos. Chem. Phys., 10, 2723-2735, doi:10.5194/acp-10-2723-2010, 2010.

Popescu, A. and Paulsen, T.: GOMOS instrument on Envisat, in: ESAMS99, European Symposium on Atmospheric Measurements from Space, vol. WPP-161, 89-99, ESA, 1999.

Press, W. H., Teukolsky, S. A., Vetterling, W. T., and Flannery, B. P.: Numerical Recipes in FORTRAN, The Art of Scientific Computing, Clarendon Press, Oxford, 1992.

Renard, J., Berthet, G., Brogniez, C., Catoire, V., Fussen, D., Goutail, F., Oelhaf, H., Pommereau, J., Roscoe, H. K., Wetzel, G., Chartier, M., Robert, C., Balois, J., Verwaerde, C., Auriol, F., François, P., Gaubicher, B., and Wursteisen, P.: Validation of GOMOS-Envisat vertical profiles of $\mathrm{O}_{3}, \mathrm{NO}_{2}, \mathrm{NO}_{3}$, and aerosol extinction using balloon-borne instruments and analysis of the retrievals, J. Geophys. Res. (Space Physics), 113, A02302, doi: 
10.1029/2007JA012345, 2008.

Roble, P. B. and Hays, R.: A technique for recovering the vertical number density profile of atmospheric gases from planetary occultation data, Planet. Space Sci., 94, 1727-1744, 1972.

Rodgers, C. D.: Inverse Methods for Atmospheric sounding: Theory and Practice, World Scientific, Singapore, 2000.

Sihvola, E.: Coupling of spectral and vertical inversion in the analysis of stellar occultation data, Geophysical publications, no. 38, Finnish Meteorological Institute, Helsinki, licentiate thesis at the University of Helsinki, Department of Theoretical Physics, 1994.

Smith, G. E. and Hunten, D. M.: Study of planetary atmospheres by absorptive occultations, Rev. Geophys., 28, 117-143, 1990.

Sofieva, V. F., Tamminen, J., Haario, H., Kyrölä, E., and Lehtinen, M.: Ozone profile smoothness as a priori information in the inversion of limb measurements, Ann. Geophys., 22, 3411-3420, doi:10.5194/angeo-22-3411-2004, 2004.

Sofieva, V. F., Kan, V., Dalaudier, F., Kyrölä, E., Tamminen, J., Bertaux, J.-L., Hauchecorne, A., Fussen, D., and Vanhellemont, F.: Influence of scintillation on quality of ozone monitoring by GOMOS, Atmos. Chem. Phys., 9, 9197-9207, doi:10.5194/acp9-9197-2009, 2009.

Sofieva, V. F., Vira, J., Kyrölä, E., Tamminen, J., Kan, V., Dalaudier, F., Hauchecorne, A., Bertaux, J.-L., Fussen, D., Vanhellemont, F., Barrot, G., and Fanton d'Andon, O.: Retrievals from GOMOS stellar occultation measurements using characterization of modeling errors, Atmos. Meas. Tech., 3, 1019-1027, doi:10.5194/amt-3-1019-2010, 2010.

Taha, G., Jaross, G., Fussen, D., Vanhellemont, F., Kyrölä, E., and McPeters, R. D.: Ozone profile retrieval from GOMOS limb scattering measurements, J. Geophys. Res.-Atmos., 113, 23307 pp., doi:10.1029/2007JD009409, 2008.

Tamminen, J. and Kyrölä, E.: Bayesian solution for nonlinear and non-Gaussian inverse problems by Markov chain Monte Carlo method, J. Geophys. Res., 106, 14377-14390, 2001.

Tamminen, J., Kyrölä, E., Sofieva, V. F., Laine, M., Bertaux, J.-L., Hauchecorne, A., Dalaudier, F., Fussen, D., Vanhellemont, F., Fanton-d'Andon, O., Barrot, G., Mangin, A., Guirlet, M., Blanot, L., Fehr, T., Saavedra de Miguel, L., and Fraisse, R.: GOMOS data characterisation and error estimation, Atmos. Chem. Phys., 10, 9505-9519, doi:10.5194/acp-10-9505-2010, 2010.
Tétard, C., Fussen, D., Bingen, C., Capouillez, N., Dekemper, E., Loodts, N., Mateshvili, N., Vanhellemont, F., Kyrölä, E., Tamminen, J., Sofieva, V., Hauchecorne, A., Dalaudier, F., Bertaux, J.-L., Fanton d'Andon, O., Barrot, G., Guirlet, M., Fehr, T., and Saavedra, L.: Simultaneous measurements of $\mathrm{OClO}, \mathrm{NO}_{2}$ and $\mathrm{O}_{3}$ in the Arctic polar vortex by the GOMOS instrument, Atmos. Chem. Phys., 9, 7857-7866, doi:10.5194/acp-9-7857-2009, 2009.

Tukiainen, S., Hassinen, S., Seppälä, A., Auvinen, H., Kyrölä, E., Tamminen, J., Haley, C. S., Lloyd, N., and Verronen, P. T.: Description and validation of a limb scatter retrieval method for Odin/OSIRIS, J. Geophys. Res.-Atmos., 113, 4308 pp., doi: 10.1029/2007JD008591, 2008.

van Gijsel, J. A. E., Swart, D. P. J., Baray, J.-L., Bencherif, H., Claude, H., Fehr, T., Godin-Beekmann, S., Hansen, G. H., Keckhut, P., Leblanc, T., McDermid, I. S., Meijer, Y. J., Nakane, H., Quel, E. J., Stebel, K., Steinbrecht, W., Strawbridge, K. B., Tatarov, B. I., and Wolfram, E. A.: GOMOS ozone profile validation using ground-based and balloon sonde measurements, Atmos. Chem. Phys., 10, 10473-10488, doi:10.5194/acp10-10473-2010, 2010.

Vanhellemont, F., Fussen, D., and Bingen, C.: Global one-step inversion of satellite occultation measurements: A practical method, J. Geophys. Res.-Atmos., 109, 9306 pp., doi:10.1029/ 2003JD004168, 2004.

Vanhellemont, F., Fussen, D., Mateshvili, N., Tétard, C., Bingen, C., Dekemper, E., Loodts, N., Kyrölä, E., Sofieva, V., Tamminen, J., Hauchecorne, A., Bertaux, J.-L., Dalaudier, F., Blanot, L., Fanton d'Andon, O., Barrot, G., Guirlet, M., Fehr, T., and Saavedra, L.: Optical extinction by upper tropospheric/stratospheric aerosols and clouds: GOMOS observations for the period 20022008, Atmos. Chem. Phys., 10, 7997-8009, doi:10.5194/acp-10-7997-2010, 2010.

Yee Jr., J.-H., R. J. V., Demajistre, R., Morgan, F., Carbary, J. F., Romick, G. J., Morrison, D., Lloyd, S. A., DeCola, P. L., Paxton, L. J., Anderson, D. E., Kumar, C. K., and Meng, C.I.: Atmospheric remote sensing using a combined extinctive and refractive stellar occultation technique, 1. overview and proof-of-concept observations, J. Geophys. Res., 107(10), 1029, doi:10.1029/2001JD000794, 2002. 